This item was submitted to Loughborough's Research Repository by the author.

Items in Figshare are protected by copyright, with all rights reserved, unless otherwise indicated.

\title{
Assessing the deflection behaviour of mechanical and insulated rail joints through finite element analysis
}

PLEASE CITE THE PUBLISHED VERSION

https://doi.org/10.1177/0954409718766925

\section{PUBLISHER}

(c) The authors. Published by SAGE Journals

\section{VERSION}

AM (Accepted Manuscript)

\section{PUBLISHER STATEMENT}

This work is made available according to the conditions of the Creative Commons Attribution-NonCommercialNoDerivatives 4.0 International (CC BY-NC-ND 4.0) licence. Full details of this licence are available at: https://creativecommons.org/licenses/by-nc-nd/4.0/

\section{LICENCE}

CC BY-NC-ND 4.0

\section{REPOSITORY RECORD}

Gallou, Maria, Matthew W. Frost, Ashraf El-Hamalawi, and Chris Hardwick. 2019. "Assessing the Deflection Behaviour of Mechanical and Insulated Rail Joints Through Finite Element Analysis”. figshare. https://hdl.handle.net/2134/32179. 


\title{
Assessing the deflection behaviour of mechanical and insulated rail joints through finite element analysis
}

\author{
M.Gallou ${ }^{1}$, M Frost ${ }^{1}$, A.El-Hamalawi ${ }^{1}$, C.Hardwick ${ }^{2}$ \\ ${ }^{1}$ Loughborough University \\ ${ }^{2}$ LB Foster Rail Technologies UK
}

\begin{abstract}
Rail joints constitute a weak component in the railway system. In this paper three- dimensional (3D) finite element analyses (FEA) are carried out to study the structural deflection performance of rail joints under a fatigue static test through vertical stiffness assessment. Four different types of 4-bolted joints are investigated under a dynamically enhanced static load including a glued insulated rail joint (IRJ), a dry encapsulated IRJ, a dry non-glued IRJ and a mechanical RJ. The analysis focused on the accurate simulation of the contact types between the interfaces of rail joint components, namely among the rail, fishplate faces, bolts, insulating materials and on the effect of the elastic supporting structure of the joint on the overall joint deflection. The effect of bolt pretension is included in the model. The vertical displacement of IRJs is measured experimentally both by dial gauges and Video technique both in laboratory and in field. The numerical modelling investigated the effect of different contact types on the interfaces of the rail joint components during the performance of fishplates, and of the rail in the vicinity of the RJ under a given support condition. The vertical displacement of the rail joint were presented and assessed against specified endurance tests' limits and field measured deflection values that validate the model. Stress distribution in the fishplates was presented that could allow the calculation, through a stress-life approach, the fatigue life of the fishplates and consequently of the joints due to repeated wheel passage. A comparison of the performance of the aforementioned RJ types is included. The results indicate this FE model to be practical to be routinely applied to industry, as it was used in UK Rail industry study to allow designers to optimise life expectancy of IRJs.
\end{abstract}

Keywords: rail joint, track structure, insulated rail joint, fishplate, 3D finite element modelling

\section{Introduction}

The main purpose of a rail joint is to join two pieces of rail where continuous rail is not possible or electrical separation is required. The structural objective of a joint is to transmit the bending moment and shear force developed from the external loads from the rail to the fishplate across the joint to the adjacent rail and subsequently to the support structure.

The rail joint is a location of weakness that deteriorates faster than surrounding track and can give rise to serious maintenance problems. Failure mechanisms of IRJs can be either electrical, mechanical or both. The dominant failure modes of rail joints in the UK are insulation (29\%) and fishplate failures (23\%) [1]. Fishplate failures include cracked or broken fishplates, bent fishplates, fishplates with a visible nib at the expansion gap; signs of wheel flanges striking fishplates can also be the reason for damage. [2]. Additionally, lipping, contamination (failed insulation) and rail defects often occur whereas fewer RJs failures are attributed to bolt failure (and/or broken bolts) and broken rails [1]. The problem of fatigue cracking in fishplates is driven by the changes in shear stresses which occur as the wheel passes across the joint. Fatigue is particularly severe in bolted joints due to the stress concentration effect on the bolt holes and the dynamic enhancement of the static wheel load due to the structural discontinuity (lower bending stiffness at the joint) [3, 4]. 
Studies of the field measurement of deformation in terms of stresses or displacements in traffic or loaded fishplate joints are limited. Literature indicates measured tension stresses in the fishplate of $110 \mathrm{MPa}$ or in 48in $(1.2 \mathrm{~m})$ fishplates under live train loading at $62 \mathrm{mph}$ of wheel-rail load $160 \mathrm{kN}$ [5] but the location of the stress measurements in the IRJ is not explained. A vertical strain value of $492 \mu$ s (that correspond to $103 \mathrm{MPa}$ ) was measured by strain gauges in the rail head $15 \mathrm{~mm}$ from the rail gap for a wheel load of $130.7 \mathrm{kN}$ during a live train passage of a velocity $46.3 \mathrm{mph}$ [6]. Recorded strain time series from glued IRJs giving a ratio of the measured strain $(\varepsilon)$ to the yield strain $\left(\varepsilon_{\mathrm{y}}\right)$ with a peak value of 0.124 (that correspond to a stress value of 105.4 $\mathrm{MPa}$ ) under measured wheel-rail forces up to $200 \mathrm{kN}$ have also been stated in the literature for strain values related to the outer web face of the fishplate [7].

Given the behaviour at rail joints it is vital to have a good understanding of their performance under load. The aim of this research was to create FE models to serve as a template for a family of rail joint designs. The structural performance of four different types of 4- hole rail joints is examined in this paper: glued IRJ (Class A), dry encapsulated IRJ (Class B), dry non glued IRJ (Class C) and mechanical RJ.

While much modelling of fishplated joints has been performed, fewer modelling papers have appropriately included support conditions. This paper seeks to address this issue (to produce a model that can be used to assess a series of joint designs) firstly describes the joints assessed then reports on literature on previous FE models of joints. From this, the FE model developed is presented and the results of each model are shown. Next, laboratory tests to validate the model are presented and finally the results are discussed. The support conditions in combination with the loading environment govern the rail joint deformation behaviour. The magnitude of deflection depends on the magnitude of vertical load and the stiffness per sleeper end used. The support environment used in the model of this paper is aligned with field recommended conditions. Softer support conditions could produce different deflection results. Additionally the bolt pretension plays an important role in the stress distribution around the fishplate holes and accounts for a significant percentage of the stresses generated in the fishplate.

Finite element analysis is an essential tool to quantify the maximum bending stress in the assembled fishplate under operational loading conditions and define the potential areas of failure. Stress results found from previous FEA studies are considered subjective to the assumptions of each FEA model and are discussed in Table 1 whereas vertical displacement of IRJs is rarely investigated in the literature [6].

\subsection{Joint types according to insulation}

Insulated rail joints are designed to insulate track sections and are classified in the UK rail network according to the insulation type and the type of track they are used for [8].

- $\quad$ Class A: glued joints suitable for CWR (continuous welded rail)

- Class B: dry (non-glued) encapsulated joints suitable for CWR

- Class C: dry (non-glued) joints for jointed track.

In all IRJs an insulating endpost is used to insulate the rail ends from each other that is commonly manufactured from nylon, epoxy fibre-glass laminated sheet or polyurethane. The glued IRJ consists of an insulating liner with an adhesive which is placed between the rail web and the fishplate. In addition the liner, ferrules and washers are fully filled with adhesive to prevent voids in the completed joint. This type of joint adds further structural integrity in the discontinuity, tend to last longer in terms of structural and electrical reliability and are used as a more permanent solution. A typical glued IRJ used in UK rail network is illustrated in Figure 1. The dry encapsulated IRJ includes steel fishplates encapsulated and bonded to an insulating elastomer material whereas the dry IRJ includes an insulating liner between the rail and the fishplate without any adhesive. The liner includes insulating ferrules of the same material that enter the fishplate holes (see Figure 2). Class A and Class B joints are used where high electrical and mechanical durability are required. Class B joints are commonly installed in switches and crossings. Class $\mathrm{C}$ are economically advantageous over the other two IRJ grades and are used in jointed and light trafficed track.

Mechanical joints are used in jointed track to join track sections when no insulation is required. A mechanical rail joint consists of the rail, the steel fishplates and 4 or 6 bolts. The two pieces of rail can be tightfastened without gaps (see Figure 33 ) or fastened with a gap typically at $6 \mathrm{~mm}$. 


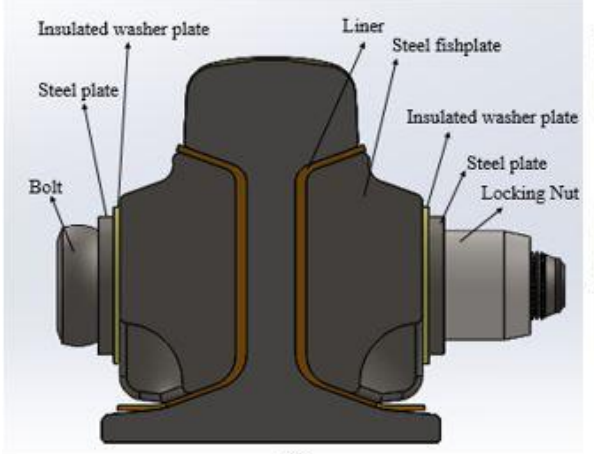

(a)

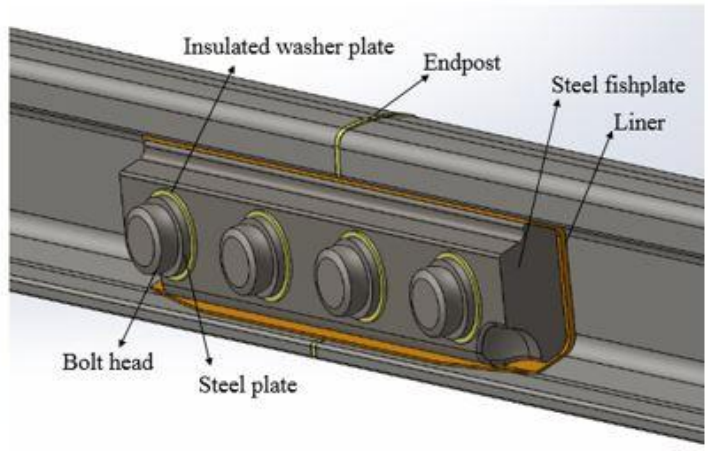

(b)

Figure 1 (a) cross and (b) front section of a glued Class A IRJ

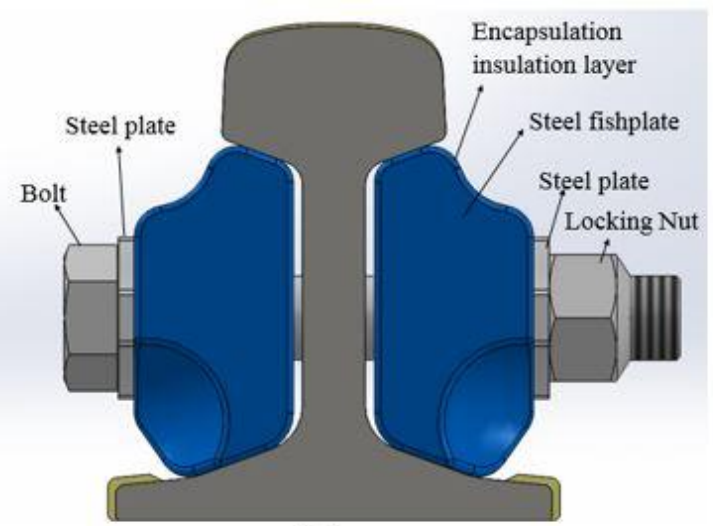

(a)

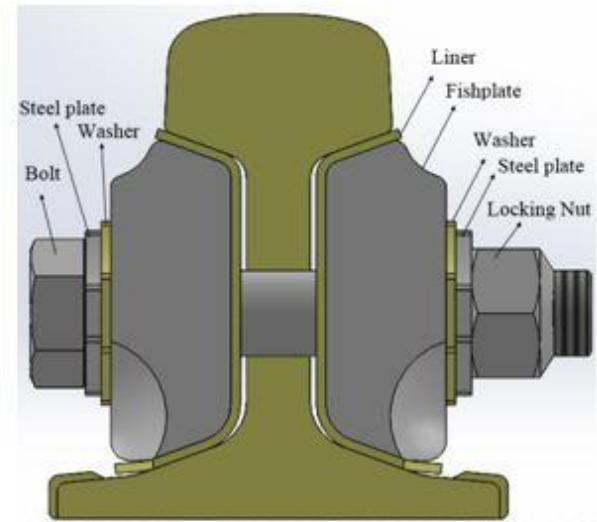

(b)

Figure 2 Cross section of (a) dry encapsulated Class B IRJ, (b) dry Class C IRJ

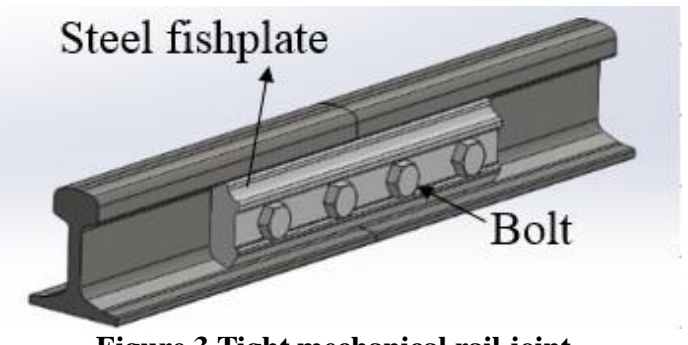

Figure 3 Tight mechanical rail joint

\subsection{Joints according to support type and number of bolt holes}

Support for joints are split into two types. A suspended joint that is an unsupported joint situated between two supports (sleepers) with regular spacing. A supported joint is situated on top of one support, one sleeper or a double sleeper. Rail joints can be 4-hole or 6-hole. 4-bolted joints are positioned in straight track or more often in turnouts or tight radius sections and near switches and crossings mainly due to space restrictions, whereas 6hole fishplates are used when the joint is needed to be as strong as possible so that the stiffness discontinuity can be reduced and are more common in tangent track.

\section{Review of modelling of IRJs}

Extensive modelling of joints has been conducted over many years. This section briefly reviews these models which are summarised in Table 1 . The majority have focused on the wheel- rail contact and the plastic deformation of railhead edges at the discontinuity $[3,9,10]$. The scope of the analysis of these models that is lipping ("localised ratchetting"), although requires a very detailed study and advanced modelling techniques, 
may not require a detailed study of the track condition supporting the rail joint (stiffness per rail bottom area or stiffness per sleeper end). However, these studies focus only on the railhead material damage. In IRJ modelling, in some instances, it is acceptable to have non-continuous (free or fixed) rail ends-for example, if only the "lipping" (localised ratchetting) is of concern. In such cases, the effect of the far edges is negligible particularly if thermal effects are disregarded $[16,17]$. In field conditions, a vicious cycle of mechanical deterioration of the rail joint and its support conditions (trackbed) occurs due to the increased dynamic loading caused by the structural discontinuity. (Hence the aim of this study is to look at wider joint deflection not just localised performance). Investigation of the structural performance of rail joints that would allow investigation of the fatigue life estimation of rail joints has been restricted to recommendations on fishplate thickness $[3,5,11]$ and endpost material [5]. Some of these models include elastic support of the rail joint $[5,11,12,13,14,15]$ but they ignore either the non-welded contact interfaces between rail, fishplate, bolts and insulating layers or the bolt pretension. Major failure modes of IRJs comprise bond failure (delamination of endpost), loosening of bolts and broken fishplates. These failure modes are attributed to the increased vertical deflection at a joint and the increased stress values experienced in the fishplates, while they are connected to the effective stiffness of a rail joint.

Another way of improving the joint life that has been investigated in the past is the inclined-cut joints, termed as "angle scarfed" joints whose rail ends are cut diagonally to the rail direction. The performance of inclined-cut joints has been investigated in the past [20] concluding lower vertical impact strains in the inclined IRJ but higher shear strains against square -cut joints, but without generalising whether they are more beneficial than square-cut joints. The inclined-cut glued IRJ has been developed in the past [21], the advantages of which were reduction of lipping in the rail head, reduction of noise and improvement of wheel transfer but there was no demonstration of fatigue life improvement for this type of joints. While investigation of inclined -cut joints has been conducted before, is beyond the scope of this paper.

Table 1 Review of previous research studies of rail joints

\begin{tabular}{|c|c|c|c|}
\hline Author & $\begin{array}{l}\text { Research } \\
\text { topic }\end{array}$ & Modelling technique & Comments \\
\hline $\begin{array}{l}\text { Solymez E. and } \\
\text { Ciloglu K., } \\
2016[5]\end{array}$ & $\begin{array}{l}\text { Effect of } \\
\text { track } \\
\text { variables in } \\
\text { IRJ }\end{array}$ & $\begin{array}{l}\text { Bonded IRJ, wheel -rail } \\
\text { dynamic analysis, 3D } \\
\text { FEA, ANSYS }\end{array}$ & $\begin{array}{l}\text { Examines only glued (bonded) IRJs under } 60 \mathrm{mph} \text {, parametric } \\
\text { analysis for fishplate stiffness, endpost material, supported vs } \\
\text { suspended IRJs, wood vs concrete ties, } 222 \mathrm{kN} \text { bolt preload. Max } \\
\text { normal stresses on fishplates on concrete ties (spacing } 609 \mathrm{~mm} \text {, } \\
\mathrm{I}_{\text {Rail }}=3931 \mathrm{~cm}^{4}, 1220 \mathrm{~mm} \text { fishplate length) up to } 200 \mathrm{MPa} \text { for a } \\
\text { wheel load } 160 \mathrm{kN} \text {. It was concluded that contact pressure resulting } \\
\text { from impact load is not affected by various track support conditions. } \\
\text { Stiffer fishplate with stiffer I } \mathrm{I}_{\text {Rail }} \text { under a lower wheel load in } \\
\text { comparison with the authors' model. Results are not comparable to } \\
\text { the authors' model. Contact pressure, contact force and rail max } \\
\text { shear stress are also examined except normal stresses in fishplates. } \\
\text { Model length } 1.5 \mathrm{~m} \text { in 3D, } 11 \mathrm{~m} \text { in 1D. }\end{array}$ \\
\hline $\begin{array}{l}\text { (Mandal NK, } \\
\text { 2016) [9], Mandal } \\
\text { NK \& Dhanasekar } \\
\text { M., 2013) [10] }\end{array}$ & $\begin{array}{l}\text { Plastic } \\
\text { deformation } \\
\text { of railhead in } \\
\text { IRJ }\end{array}$ & $\begin{array}{l}\text { 3D FEA, ABAQUS, } \\
\text { plastic deformation of } \\
\text { railhead, non-linear } \\
\text { isotropic and kinematic } \\
\text { material hardening model } \\
\text { for } 2000 \text { cycles }\end{array}$ & $\begin{array}{l}\text { 6-bolt suspended IRJ, account for bolt pretension } 200 \mathrm{kN} .700 \mathrm{~mm} \\
\text { spacing, 3D part } 2.4 \mathrm{~m}, 9.6 \mathrm{~m} \text { in } 1 \mathrm{D} \text {. } 174 \mathrm{kN} \text { wheel load. Too low } \\
\text { vertical displacement }(0.2 \mathrm{~mm}) \text {. Sleepers fixed with zero degrees of } \\
\text { freedom not representative of field conditions in contrast with the } \\
\text { authors' model. Model representative of a laboratory experiment of } \\
\text { rail joint. Though aim of this paper is the plastic zone of the top } \\
\text { surface of rail head material. }\end{array}$ \\
\hline $\begin{array}{l}\text { (Grossoni I. et al., } \\
\text { 2014) [12] }\end{array}$ & $\begin{array}{l}\text { Dynamic } \\
\text { response at a } \\
\text { RJ }\end{array}$ & $\begin{array}{l}\text { 2D FEA vehicle -track } \\
\text { coupling model, track } \\
\text { system: rail as beam on a } \\
\text { double-layer discrete } \\
\text { viscous -elastic } \\
\text { foundation, idealised form } \\
\text { of rail irregularity (IRJ) } \\
\text { through quadratic function } \\
\text { (second order polynomial) }\end{array}$ & $\begin{array}{l}\text { 2D model includes } 3 \text { parameters of IRJs (joint max deflection, joint } \\
\text { angle and joint length) by using a mathematical idealisation of } \\
\text { dipped beam in 2D. It shows that the joint shape plays role in the } \\
\text { magnitude of P2 force that actually affects the track degradation. } \\
\text { The model does not allow looking in neither the interfaces of RJ } \\
\text { components, nor the structural investigation of the RJ. The joint } \\
\text { deformation is used as input for wheel -rail impact forces } \\
\text { calculation. }\end{array}$ \\
\hline $\begin{array}{l}\text { (Bandula-Heva } \\
\text { TM, Dhanasekar } \\
\text { M. \& Boyd P., } \\
\text { 2012) [16] }\end{array}$ & $\begin{array}{l}\text { Wheel/rail } \\
\text { rolling } \\
\text { contact at } \\
\text { railhead edge }\end{array}$ & $\begin{array}{l}\text { 3D FEA validated by PIV } \\
\text { and strain gauges in } \\
\text { laboratory }\end{array}$ & $\begin{array}{l}\text { FE model of wheel-railhead-rail body (without full IRJ assembly) to } \\
\text { simulate laboratory conditions of half of IRJ under loaded wheel } \\
\text { passage to determine railhead vertical, lateral and shear strain } \\
\text { components. Used to investigate railhead edge behaviour due to } \\
\text { accumulation of plastic deformation. }\end{array}$ \\
\hline
\end{tabular}




\begin{tabular}{|c|c|c|c|}
\hline $\begin{array}{l}\text { Bandula-Heva } \\
\text { TM \& } \\
\text { Dhanasekar M., } \\
\text { 2014) [17] }\end{array}$ & $\begin{array}{l}\text { Localised } \\
\text { plastic strain } \\
\text { accumulation } \\
\text { in railhead } \\
\text { edge }\end{array}$ & $\begin{array}{l}\text { 3D FEA of railhead edge } \\
\text { using Caboche kinematic } \\
\text { hardening law using } \\
\text { experimental uniaxial } \\
\text { monotonic tension tests of } \\
\text { railhead coupons. }\end{array}$ & $\begin{array}{l}\text { FE model validated as abovementioned in Ref } 16 \text { used to predict } \\
\text { localised plastic strain in railhead edge.. }\end{array}$ \\
\hline $\begin{array}{l}\text { (Zong N. et al., } \\
\text { 2013) [13] }\end{array}$ & $\begin{array}{l}\text { Wheel -rail } \\
\text { contact } \\
\text { impact } \\
\text { loading of } \\
\text { IRJ }\end{array}$ & $\begin{array}{l}\text { Wheel rail contact impact } \\
\text { model, 3D FEA }\end{array}$ & $\begin{array}{l}\text { Account for wheel-rail frictional contact, } 200 \mathrm{kN} \text { bolt preload, } \\
\text { elastic support per rail end. Model examines the contact and impact } \\
\text { force, contact pressure, validated against vertical strain in rail web } \\
\text { with field test. It doesn't present structural performance of the joint } \\
\text { in terms of deflection, stresses on fishplate, does not comment on } \\
\text { how the rail-fishplate interfaces were modelled. A modal analysis } \\
\text { was carried out indicated the frequency of the impact force has been } \\
\text { dominated on its seventh mode. Railhead damage was indicated in } \\
\text { the model in form of reduced gap, vertical dip and residual stress of } \\
\text { rail end sample was analysed using Neutron diffraction technique. }\end{array}$ \\
\hline $\begin{array}{l}\text { Patel Q., Kumar } \\
\text { V. and Nareliya } \\
\text { R., 2013) [14] }\end{array}$ & $\begin{array}{l}\text { Fatigue life } \\
\text { estimation of } \\
\text { RJ using } \\
\text { FEA }\end{array}$ & $\begin{array}{l}\text { Wheel-rail dynamic 3D } \\
\text { FEA, standard RJ. }\end{array}$ & $\begin{array}{l}\text { Model included a mechanical non-inuslated RJ on a two sleeper } \\
\text { configuration on elastic support. Lack of symmetry and short length } \\
\text { of model may affect the results. Mesh is not presented. Contact } \\
\text { type in between rail-fishplates that is usually frictional for the } \\
\text { standard RJ is not commented. Bolts were modelled with solid } \\
\text { elements. A max Von Mises stress of } 214 \text { MPa was found in rail } \\
\text { joint. }\end{array}$ \\
\hline $\begin{array}{l}\text { (Mandal NK \& } \\
\text { Peach B., 2010) } \\
\text { [3] }\end{array}$ & FEA of IRJ & $\begin{array}{l}\text { Static 3D FEA of a } 6 \text {-bolt } \\
\text { IRJ, objective to } \\
\text { investigate the effect of } \\
\text { fishplate width on stresses } \\
\text { in railhead. }\end{array}$ & $\begin{array}{l}\text { Fixed support on rail bottom, rail was tied to the sleepers, no } \\
\text { interaction between rail and fishplate, welded joint. Effect of } \\
\text { fishplate width in stresses on railhead and in deflection was } \\
\text { investigated. Too stiff conditions indicated very low deflection } \\
\text { results. }\end{array}$ \\
\hline $\begin{array}{l}\text { (Sandström J. \& } \\
\text { Ekberg A, 2009) } \\
\text { [18] }\end{array}$ & $\begin{array}{l}\text { Fatigue } \\
\text { impact and } \\
\text { plastic } \\
\text { deformation } \\
\text { of IRJ }\end{array}$ & $\begin{array}{l}\text { 3D FEA of IRJ, wheel rail } \\
\text { contact, non-linear } \\
\text { kinematic hardening } \\
\text { constitutive model }\end{array}$ & $\begin{array}{l}\text { Model indicates that the main failure mechanism of IRJs is } \\
\text { ratcheting and not the low cycle fatigue. Model included only part } \\
\text { of wheel, railhead edges and endpost. Effect of increase of frictional } \\
\text { coefficient between rail and wheel, increase of endpost thickness } \\
\text { and effect of rail edge bevelling under multiaxial loading conditions } \\
\text { on the total accumulated plastic strain in rail are investigated. }\end{array}$ \\
\hline $\begin{array}{l}\text { (Himebaugh AK } \\
\text { et al, 2007) [11] }\end{array}$ & $\begin{array}{l}\text { FEA of } \\
\text { bonded IRJ }\end{array}$ & $\begin{array}{l}\text { Static 3D FEA of } \\
\text { supported IRJ in } \\
\text { ABAQUS }\end{array}$ & $\begin{array}{l}\text { One type of supported bonded IRJ. Model included fishplate of } \\
\text { length } 1.2 \mathrm{~m} \text {, no rigid bolts modelled, wooden sleepers and elastic } \\
\text { foundation. A model length of } 7.6 \mathrm{~m} \text { was considered sufficient to } \\
\text { model on each side of the wheel after parametric analysis. Effect of } \\
\text { thickness and length of joint bar, load position and size of sleepers } \\
\text { on rail deflection and epoxy stresses are investigated under vertical } \\
145 \mathrm{kN} \text { and tensile } 1330 \mathrm{kN} \text { load in the rail. Tensile load is not } \\
\text { commented how it was selected, whether it corresponds to the } \\
\text { tension force of the bolt preload in the area of joint or not. }\end{array}$ \\
\hline $\begin{array}{l}\text { (Ding K. \& } \\
\text { Dhanasekar M., } \\
\text { 2007) [19] }\end{array}$ & $\begin{array}{l}\text { Flexural } \\
\text { behaviour of } \\
\text { bonded- } \\
\text { bolted butt } \\
\text { joints due to } \\
\text { bolt } \\
\text { looseness }\end{array}$ & $\begin{array}{l}\text { ABAQUS 3D FEA, pre- } \\
\text { stressing of bolts, inplane } \\
\text { bending in bolted IRJ. }\end{array}$ & $\begin{array}{l}\text { Elasto-plastic material law for fishplates only, elastic law for the } \\
\text { rest. Bonded connections among rail-fishplates-bolts, bolt preload is } \\
\text { accounted. Effect of looseness of bolts under biaxial stress on the } \\
\text { RJ. }\end{array}$ \\
\hline $\begin{array}{l}\text { (Talamini B. et al, } \\
\text { 2007)[15] }\end{array}$ & $\begin{array}{l}\text { Fatigue } \\
\text { estimation of } \\
\text { fishplates }\end{array}$ & $\begin{array}{l}\text { Static 3D FEA in } \\
\text { ABAQUS, wheel rail } \\
\text { contact, 6-bolted RJ. }\end{array}$ & $\begin{array}{l}\text { Static analysis with load increased with dynamic factor, mechanical } \\
\text { non-insulated RJ, elastic support, theoretical estimation of bending } \\
\text { stresses on fishplate and thermal stresses, FE estimation of biaxial } \\
\text { bending and reverse bending stresses on fishplates, fatigue } \\
\text { estimation of fishplates. }\end{array}$ \\
\hline
\end{tabular}

Most previous FEA studies of rail joints consider a joint as a bonded assembly. No modelling was found describing the structural performance of various types of less stiff, four bolted rail joints under a critical dynamic load case looking at the frictional contact in rail/fishplate/insulating layer interfaces within the aim of assessing the fatigue life of joints due to mechanical failure of fishplates and thus assessing their resistance to bending and their vertical stiffness/deflection. Previous modelling by the authors has shown that the elastic support conditions produce displacement values that are in a good agreement with field data measured with a high accuracy video technique under high speed traffic [22]. 


\section{FEA model}

\subsection{Material properties, contacts and boundary conditions}

A model was therefore developed to address some of the issued identified above from past work, to produce a practical and routine validated model that could be used by industry to assess the overall deflection and likely implication on joint life including an estimation of underlying trackbed support. This section reports the model developed to include support stiffness. ANSYS Mechanical was used to perform 3D static structural analysis of the joints identified in Section 1. The basic model included four CEN 56 rails of moment of inertia $2320.0 \mathrm{~cm}^{4}$ of $2 \mathrm{~m}$ each covering a length of six sleepers. The sleeper spacing was set as $700 \mathrm{~mm}$ and the track gauge as $1435 \mathrm{~mm}$. A railpad of thickness $10 \mathrm{~mm}$ and of medium stiffness $(150 \mathrm{kN} / \mathrm{mm})$ was used between the rail and the sleeper that acts as a resilient spring to vertical movement of the rail (that includes uplift). Bonded contact was applied between the rail and the railpad (it is considered that the use of fastening clips would add value to the model in case of rail subjected to longitudinal and lateral forces but is not included in this paper). A nonlinear contact type between rail and railpad was ignored, as it is considered that the toe load of a fastening clip would provide some vertical resilience to uplift. Two loading cases were initially studied in order to assess the fishplate "sagging" and "hogging" deformation. The load case presented here (see Figure 4) includes a wheel load of $200 \mathrm{kN}$ applied as a nodal force on top of the centre of railhead at a distance of $10 \mathrm{~mm}$ from the rail gap. This will give maximum compressive stress at the top of the fishplate (sagging deformation). This load case is prescribed by the national UK rail operator and accords with the maximum static load in UK rail infrastructure (25 tonne axle load), increased by a dynamic factor of 1.6 [23]. The purpose of this research was to create models that would serve as template for a family of rail joint designs for design studies. A further study of hogging performance will be the subject of a further publication. Nodal force was used over an area that corresponds to the wheel-rail contact patch according to Hertzian contact.

The steel of rail and fishplates has a yield strength $\left(\mathrm{S}_{\mathrm{y}}\right) 850 \mathrm{MPa}$ [24]. The tensile strength of the steel used was set at $1150 \mathrm{MPa}$. Bonded contact was applied between the rail pads and the sleepers. Concrete G44 sleepers were used with a cant $1 / 20$. All components are modelled with solid elements.

For the accurate simulation of the elastic behaviour of soil-track interaction, the principle of Winkler (1867) was followed, according to which the use of springs is suggested with spring stiffnesses selected according to the support flexibility underneath the sleepers. The springs were connected in an effective length in both the sides of the sleeper bottom. The length is considered effective at both sides of the load position that is equal to $\mathrm{Lp}=(\mathrm{L}-$ c) $/ 2=500.1 \mathrm{~mm}$, where $\mathrm{L}$ is the sleeper length and $\mathrm{c}$ the rail seat spacing. This assumption better simulates the fact that monoblock sleepers are packed over an area on either side of the centre of the rail [25]. A minimum dynamic sleeper support stiffness of $30 \mathrm{kN} / \mathrm{mm}$ per sleeper end has been used as defined for a renewed track bed [26].

The rational selection of the boundary conditions plays an important role in the creation of a functional FE model. For this reason the following constraints were applied:

- In the position of the springs, stiffness was applied in the Y direction.

- As far as the rail ending faces of the model are concerned, displacement constraints were applied in the $\mathrm{X}$ and $\mathrm{Z}$ direction to prevent rigid-body motions, allowing free movement in $\mathrm{Y}$ direction. The sum of the reaction forces at the constraint points are zero. No part of the rail ending faces can move, rotate or deform in the $\mathrm{X}$ and $\mathrm{Z}$ direction. The deflection in all model configurations in this study at the rail ends was shown to be almost zero (see Figure 19). Boundary conditions were applied to at least three sleepers from the position of the load. The authors tested in a preliminary study the length of the model and this was shown to be suitable as not to affect the deflection bowl of the joint.

Table 22 describes the material properties assigned to the different components. Figure 5 shows the geometry and meshing of the model. A refined mesh of maximum size $8 \mathrm{~mm}$ was applied in the rail joint vicinity and in the load application areas. The majority of elements used in all IRJ models in this study is higher order 3-D, 10-node tetrahedral quadratic element SOLID187 that has a quadratic displacement behaviour (shape function) and do not suffer from shear locking. This type of element is well suited to modelling irregular meshes such as those produced from complex CAD geometries with curved outlines and complex contact surfaces. A smaller part of the mesh was hexahedral 20-node of quadratic shape elements. The authors carefully tested the 10-node against 20-node quadratic elements under same element size in a four-point bend test and no difference in the deflection and stress results was observed. Only linear shape function suffers from shear locking and poor bending deformation characteristics, so shear locking is not considered an issue. 


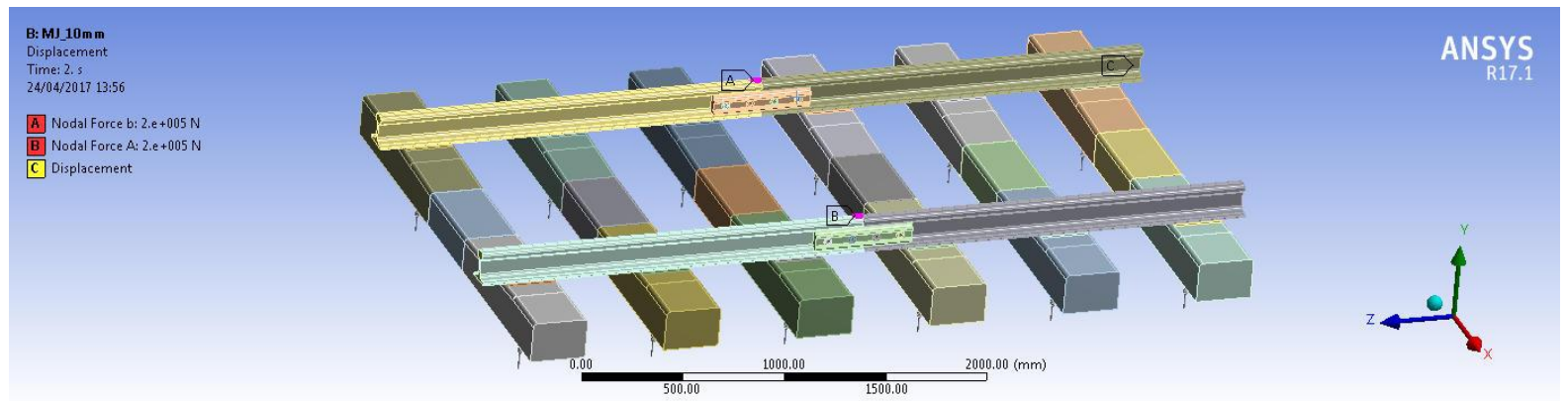

Figure 4 View of the model showing the loading positions at $10 \mathrm{~mm}$ from the rail end.

Table 2 Elastic Material Properties

\begin{tabular}{|l|l|l|l|l|l|}
\hline Component & Material & Stiffness & Modulus of Elasticity & $\begin{array}{l}\text { Poisson's } \\
\text { ratio }\end{array}$ & Density \\
\hline & & $\mathrm{k}$ & $\mathrm{E}$ & $\mathrm{v}$ & $\rho$ \\
\hline Rail, Fishplate & Steel & & $210 \mathrm{GPa}$ & 0.3 & $7850 \mathrm{~kg} / \mathrm{m}^{3}$ \\
\hline Railpad & Elastomer & $150 \mathrm{MN} / \mathrm{m}$ & $38.265 \mathrm{MPa}$ & 0.3 & $300 \mathrm{~kg} / \mathrm{m}^{3}$ \\
\hline Sleeper & Concrete & & $30 \mathrm{GPa}$ & 0.18 & $2300 \mathrm{~kg} / \mathrm{m}^{3}$ \\
\hline Endpost & Polyurethane & & $20.7 \mathrm{MPa}$ & 0.3 & $1265 \mathrm{~kg} / \mathrm{m}^{3}$ \\
\hline
\end{tabular}

\subsection{Bolt pretension}

The effects of bolt pre-tension are accounted for in the model. Beam elements were used to provide shear resistance to vertical load [27]. These elements were then given a pre-load value equivalent to the expected preload generated from the tightening torque permissible on a Grade 8.8, M24 (or M27 dependent on joint design) bolt. The pre-load was calculated from the equation:

$F=\frac{T}{K * d}$

where $\mathrm{T}$ is the permissible tightening torque, $\mathrm{d}$ the bolt diameter and $\mathrm{K}$ a bolting coefficient with a value of 0.2 (156 kN for M24 and $184 \mathrm{kN}$ for M27).

This load was applied as part of a multi-step analysis in the model, with a total duration of 2 seconds. The bolt pre-load was applied as a ramped load over the course of 1 second - to mimic the effects of assembling the joint and tightening fasteners. The vertical load, of $200 \mathrm{kN}$, was then subsequently applied as a load for a duration of 1 second. The second load step applies the load gradually over 5 to 10 substeps, each substep uses up to 50 equilibrium iterations for an accurate solution to be obtained.

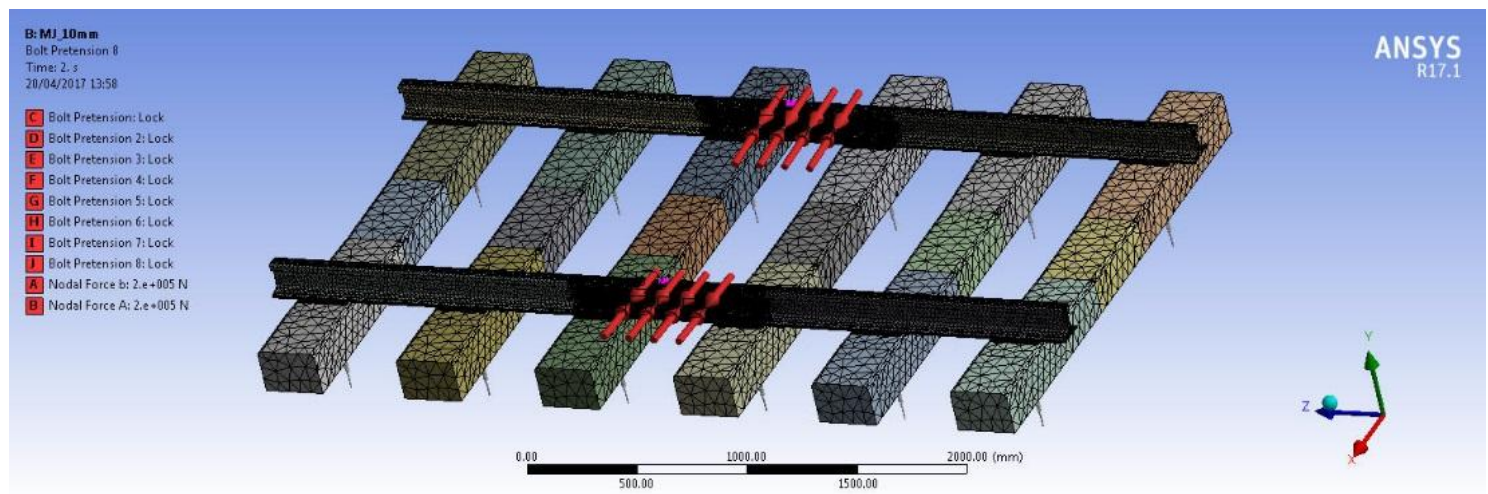

Figure 5 Model layout showing bolt preload and mesh 


\subsection{Numerical model configurations}

Table 3 presents the different configurations modelled: (a) glued IRJ-Class A, (b) mechanical RJ, (c) dry (encapsulated) IRJ- Class B and (d) dry (non-glued) IRJ- Class C. All joints were 4-bolted. Insulating liners are of $3 \mathrm{~mm}$ thickness and the encapsulation layer is a resin coating of thickness $3 \mathrm{~mm}$. The fishplate properties of the configurations studied are described in Table 4. The material properties of the insulating layers that varied along the RJ types are presented in Table 5.

Table 3 Model configurations

\begin{tabular}{|l|l|l|l|l|}
\hline \multirow{2}{*}{ Joint type } & \multicolumn{2}{|l|}{ Rail combination at joint } & \multirow{2}{*}{ No Holes } & Fishplate type \\
\cline { 2 - 3 } & Rail section 1 & Rail section 2 & & \\
\hline Glued & CEN56 & CEN56 & 4-hole & Insulated Class A \\
\hline Mechanical & CEN56 & CEN56 & 4-hole & Standard \\
\hline Dry & CEN56 & CEN56 & 4-hole & Insulated (encapsulated) Class B \\
\hline Dry & CEN56 & CEN56 & 4-hole & Insulated (non-glued) Class C \\
\hline
\end{tabular}

Table 4 General fishplate properties

\begin{tabular}{|c|c|c|c|c|c|c|}
\hline & Property & Length & $\begin{array}{l}\text { Fishplate } \\
\text { hole } \\
\text { diameter }\end{array}$ & Mass & $\begin{array}{l}\text { Moment of } \\
\text { inertia } I_{x x}\end{array}$ & $\begin{array}{l}\text { Cross } \\
\text { sectional } \\
\text { area } \\
\end{array}$ \\
\hline & Units & $\mathrm{mm}$ & $\mathrm{mm}$ & $\mathrm{kg}$ & $\mathrm{cm}^{4}$ & $\mathrm{~mm}^{2}$ \\
\hline \multirow{6}{*}{ 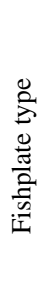 } & Insulated Class A-CEN 54E1-6H (3pb) & 800 & 32 & 22.707 & 242.554 & 3613.22 \\
\hline & Insulated Class A-CEN60-4H (4pb) & 650 & 35.5 & 21.65 & 264.768 & 3966.91 \\
\hline & Standard Mechanical CEN 56- $4 \mathrm{H}$ & 507 & 25.5 & 14.69 & 298.08 & 3871.03 \\
\hline & Insulated Class A CEN 56-4H & 508 & 35.5 & 15.47 & 210.20 & 3684.12 \\
\hline & Insulated encapsulated Class B CEN 56-4H & 508 & 36 & 16.40 & 237.85 & 3703.47 \\
\hline & Insulated non glued Class C CEN 56-4H & 508 & 36 & 12.65 & 252.12 & 3499.79 \\
\hline
\end{tabular}

Table 5 Material properties of insulation materials

\begin{tabular}{|l|l|c|c|}
\hline \multicolumn{3}{|c|}{ Material properties } \\
\hline Component & \multicolumn{1}{|c|}{ Material } & $\begin{array}{c}\text { Modulus of } \\
\text { Elasticity }\end{array}$ & Poisson's ratio \\
\hline $\begin{array}{l}\text { Insulation layer_Class A \& } \\
\text { C (Pultruded liner) }\end{array}$ & Glass Fibre Reinforced Polyester Resin & $8000 \mathrm{MPa}$ & 0.38 \\
\hline Insulated washer & Epoxy Glass Sheet G10 & $2400 \mathrm{MPa}$ & 0.35 \\
\hline Encapsulation layer-Class B & Altech & $2100 \mathrm{MPa}$ & 0.39 \\
\hline Ferrule Class A & Epoxy Glass Sheet G10 & $2400 \mathrm{MPa}$ & $1850 \mathrm{~kg} / \mathrm{m}^{3}$ \\
\hline Ferrule Class C & Glass Fibre Reinforced Polyester Resin & $8000 \mathrm{MPa}$ & $1090 \mathrm{~kg} / \mathrm{m}^{3}$ \\
\hline
\end{tabular}

The varying FE assumptions among the varying RJ types are described below. The meshing, loading, bolt pretension and boundary conditions were applied in the same manner as described above.

\subsubsection{Glued Insulated Rail Joint-Class A}

The Classification A joint configuration includes an insulating liner that electrically separates the steel and is glued to both the fishplate and the rail. Pultruded Glass Fibre Reinforced Polyester Resin is used in this study as a liner. Bonded contact was applied between the fishplate and the insulated washers and ferrules. Bonded contact was also applied between the rail/liner /fishplate interfaces to simulate the glued faces (see Figure 6). 


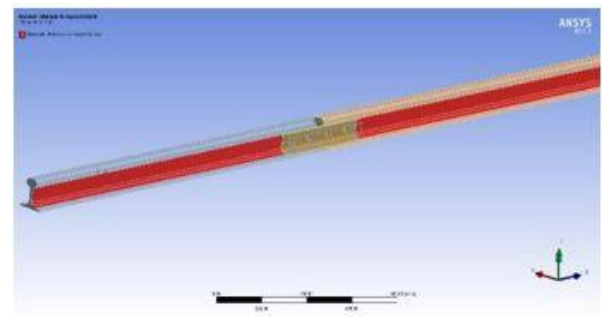

(a)

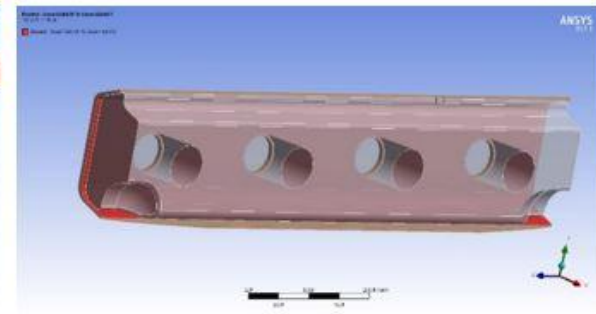

(b)

Figure 6 Bonded contact between (a) the rail and liner and (b) the fishplate and the liner to simulate glue.

\subsubsection{Mechanical Rail Joint}

Only the upper and lower "fishing "surfaces of the rail were given frictional contact with the fishplates(s) with a coefficient of friction 0.2 (see Figure 7) with a gap existing between the rail web and fishplate.

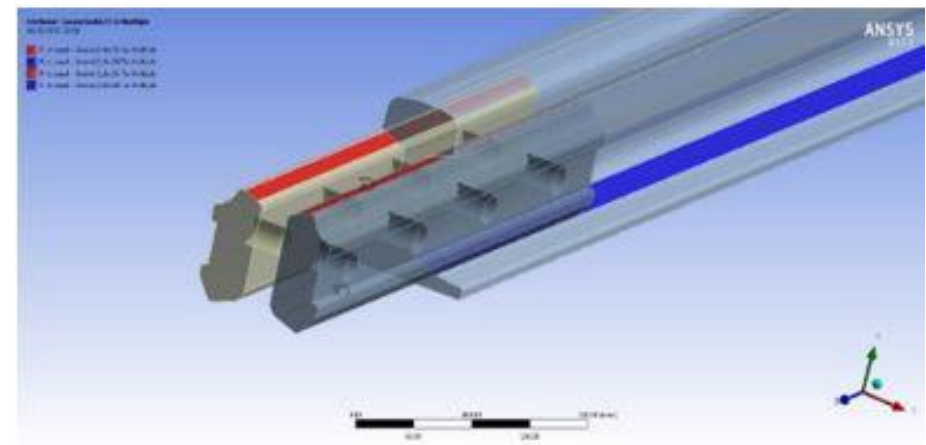

Figure 7 Frictional contact between rail and standard fishplate.

\subsubsection{Dry encapsulated Insulated Rail Joint-Class B}

The fishplate is fully encapsulated in an elastomer material. The material used is ALTECH PA6 A 1000/310 IM. Frictional contact was applied between the upper and lower "fishing" faces of the rail and the fully encapsulated plates with a coefficient of friction 0.2 in the same way as in the mechanical RJ (see Figure 8). Bonded contact was applied between the encapsulation layer and the steel fishplate.

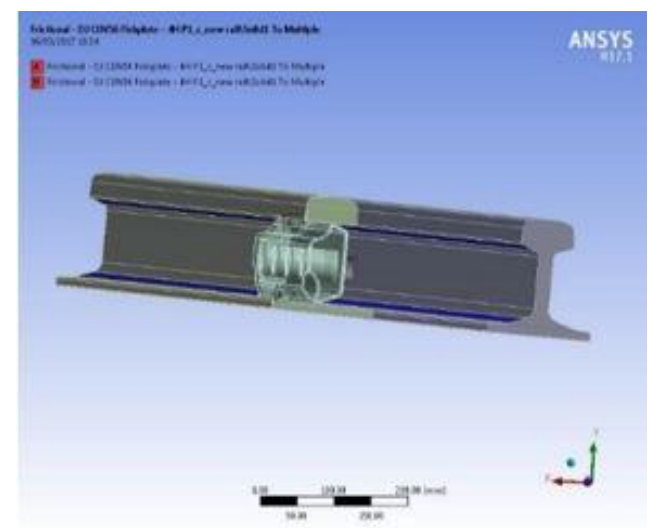

Figure 8 Frictional contact between rail and fully encapsulated fishplate

\subsubsection{Dry non-glued Insulated Rail Joint-Class C}

A Pultruded Glass Fibre Reinforced Polyester Resin was used in this study as a liner between the rail and the fishplates. Contacts between the upper and lower fishing faces of the rail with the liner were given frictional contact of 0.2. Frictional contact was given between all inside faces of the liner with the fishplates and between the fishplate hole faces and the insulated ferrules (see Figure 9). 

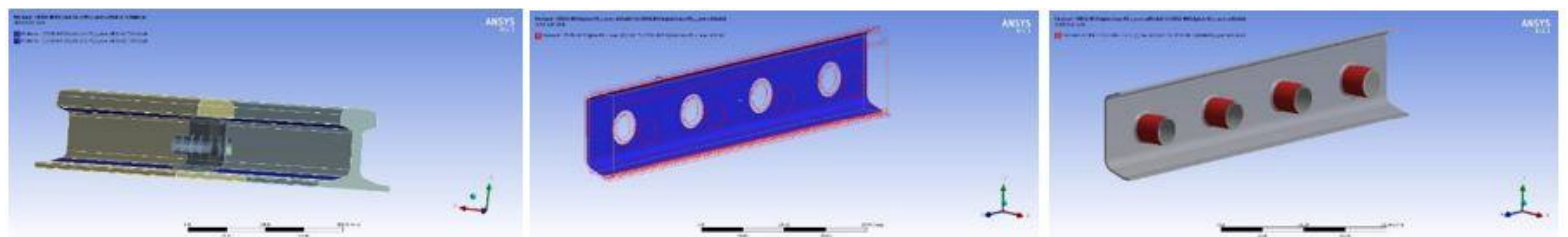

Figure 9 Frictional contact between (a) rail and liner top and bottom fishing surfaces, (b) liner and fishplate and (c) faces of insulated ferrules (incorporated with the liner) to that of the fishplate.

This model had an increased number of frictional contacts inserting non-linearities in the model that are in combination with: a) the large size of the model, b) the existence of multiple bolt loads and c) the complexity of the load sequence aggravated the solution to converge. Thus, both load steps applied the load gradually over 25 sub steps, each sub step uses up to 25 equilibrium iterations (see Figure 10). An advanced contact formulation was used to enforce compatibility at the non-linear frictional contact interfaces. Augmented Lagrange formulation with a normal stiffness factor 0.01 updated on the end of each equilibrium iteration was used for the non-linear solid body contact of faces adding additional controls to automatically reduce contact penetration allowing contact detection at integration points [28]. These analysis settings allowed the establishment of a relationship between two faces of frictional contact region to prevent them from passing through each other. The software for such a contact formulation based on a pure penalty method assumes that the contact force along the normal direction is written as follows:

$F_{\text {normal }}=\mathrm{k}_{\text {normal }} * x_{\text {penetration }}$

Where $\mathrm{k}_{\text {normal }}$ is the contact stiffness, $\mathrm{x}_{\text {penetration }}$ is the distance between two existing nodes on separate contact bodies, $\mathrm{F}_{\text {normal }}$ the contact force [28].

In addition, an interface treatment was used adjusting the initial position of the reference and target contact surfaces to eliminate any gaps or penetrations formatted during loading for the non-linear contact types. This setting automatically calculates an offset based on the minimum gap between two non-parallel faces to close the contact region allowing localised contact [28].
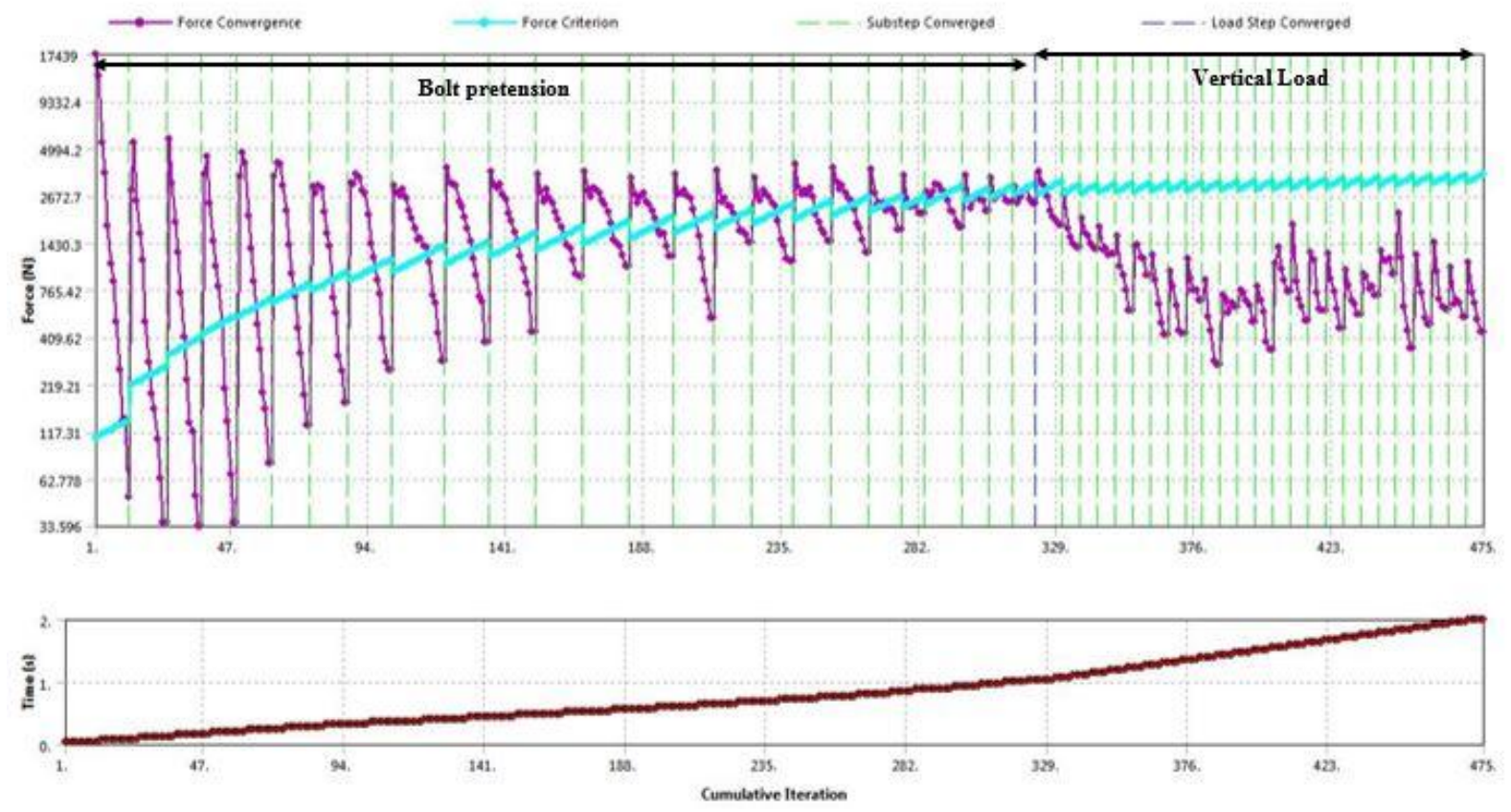

Figure 10 Force convergence along the solution of IRJ Class C.

\section{Experimentation and Laboratory validation}

Validation of the FE model was conducted in terms of quantifying the accuracy of the model by comparing numerical solutions to experimental data. Initially joint deflections were compared between a laboratory 3-point 
bend test and the corresponding FE model. FE model was also validated in terms of joint deflections measured by the high definition Video Gauge technique in a 4-point bend test. A strain comparison among FEA and experimental data while useful was not part of this study. This would require a more complex laboratory set up with strain gauges. The assessment of strain from the Video Gauge in rail joints may be possible it has not been validated yet and both elements were outside the scope of this work. In addition, in IRJ worldwide specifications $[8,29,30,31,32]$ the mechanical performance of rail joints is approved by bending fatigue endurance tests where deflection limits are used as the acceptance criterion for the assessment of their structural stiffness and response to vertical load, hence why deflection was assessed in this study as a primary routine validator.

\subsection{3-point bend testing}

A 6-bolt glued IRJ Class A of $1.3 \mathrm{~m}$ length with rail section CEN54E1 with an endpost of 8 mm thickness was tested in a three-point bend under static loading. The geometrical characteristics of the fishplate are presented in Table 4 of section 3.3. The load was applied $13 \mathrm{~mm}$ away from the centre of the joint to avoid the joint gap. The vertical displacement was recorded through dial gauges placed on top of the railhead in several positions on each rail section (see Figure 11) giving in total 9 readings for each load case. The loading occurred in steps from $20 \mathrm{kN}$ to $200 \mathrm{kN}$. A static FE model was created to simulate the three-point bend test based on the above (Section 3). The vertical displacement in $\mathrm{Y}$ axis was set to zero in the two end edges of rail foot in the position of supports as shown in Figure 12. Bonded contact was applied among all interfaces of the glued IRJ components. The model had a minimum mesh size of $8 \mathrm{~mm}$ and the model included 476929 nodes and 295687 elements running in a computational time of $2 \mathrm{~h} 37 \mathrm{~min}$. A parametric analysis was performed to assess the magnitude of deflection with a mesh that would reduce the computational time and it was concluded that a coarser mesh with minimum element size of $16 \mathrm{~mm}$ provided the same deflection results. Thus, the basic loading case of $200 \mathrm{kN}$ was performed in an 8mm maximum element mesh and the parametric analysis of $20 \mathrm{kN}$ to 180 $\mathrm{kN}$ was performed in the model with a coarser mesh. An exaggerated deflection shape of the FE model is shown in Figure 13.

Very good correlation was found between experimental and FEA deflection data. A comparison is presented in Figure 14 for the vertical displacement at the central path along the top surface of railhead. A difference of 2$10 \%$ for the various load cases was found showing that the model represents quite accurately the complex deflection histories of the rail joint.
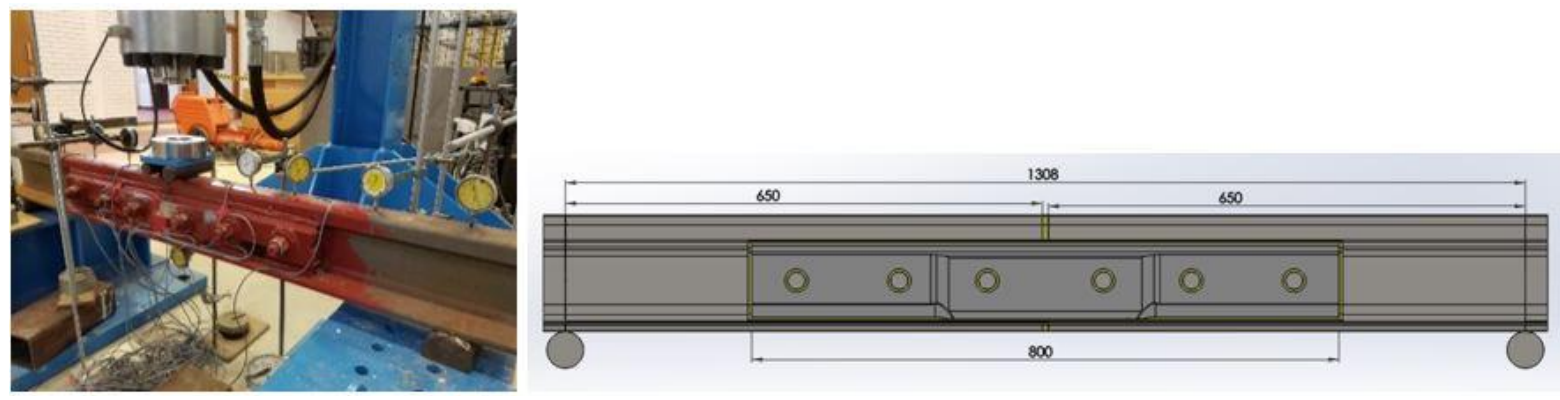

Figure 11 (a) Laboratory 3-point bend test showing set-up and position of dial gauges (b) Geometry of the 3-point bend configuration

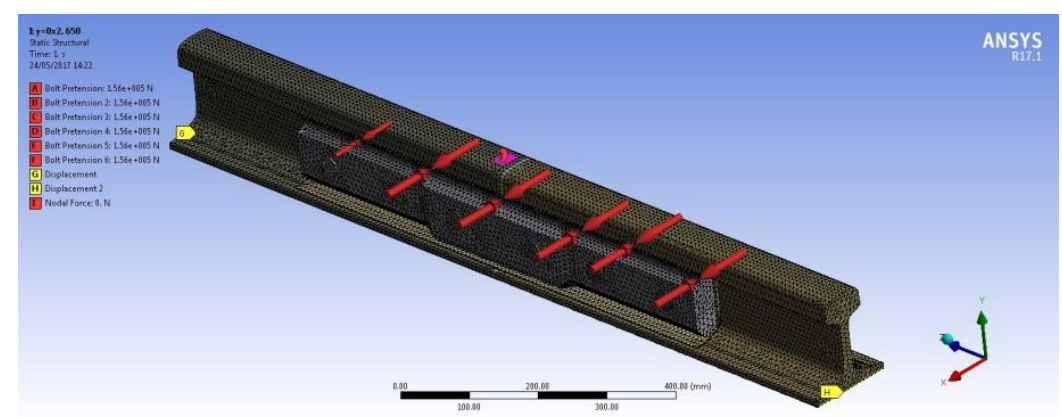

Figure 12 Mesh and boundary conditions of the 3-point bend FE model 


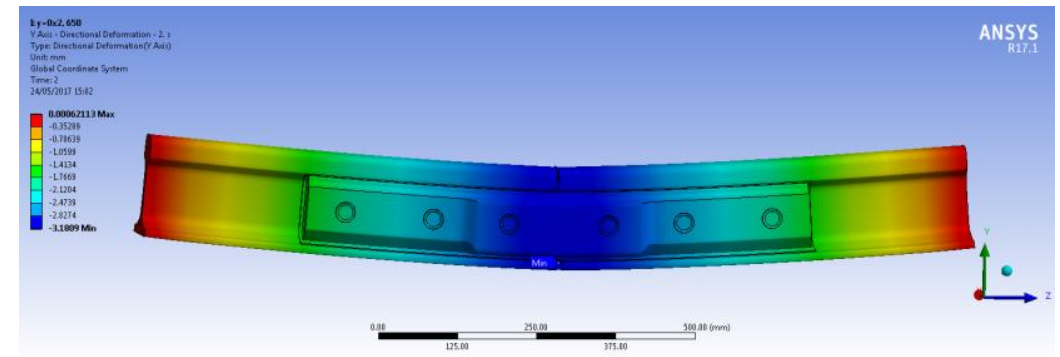

Figure 13 Exaggerated deformed deflection shape of the 3-point bend FE model
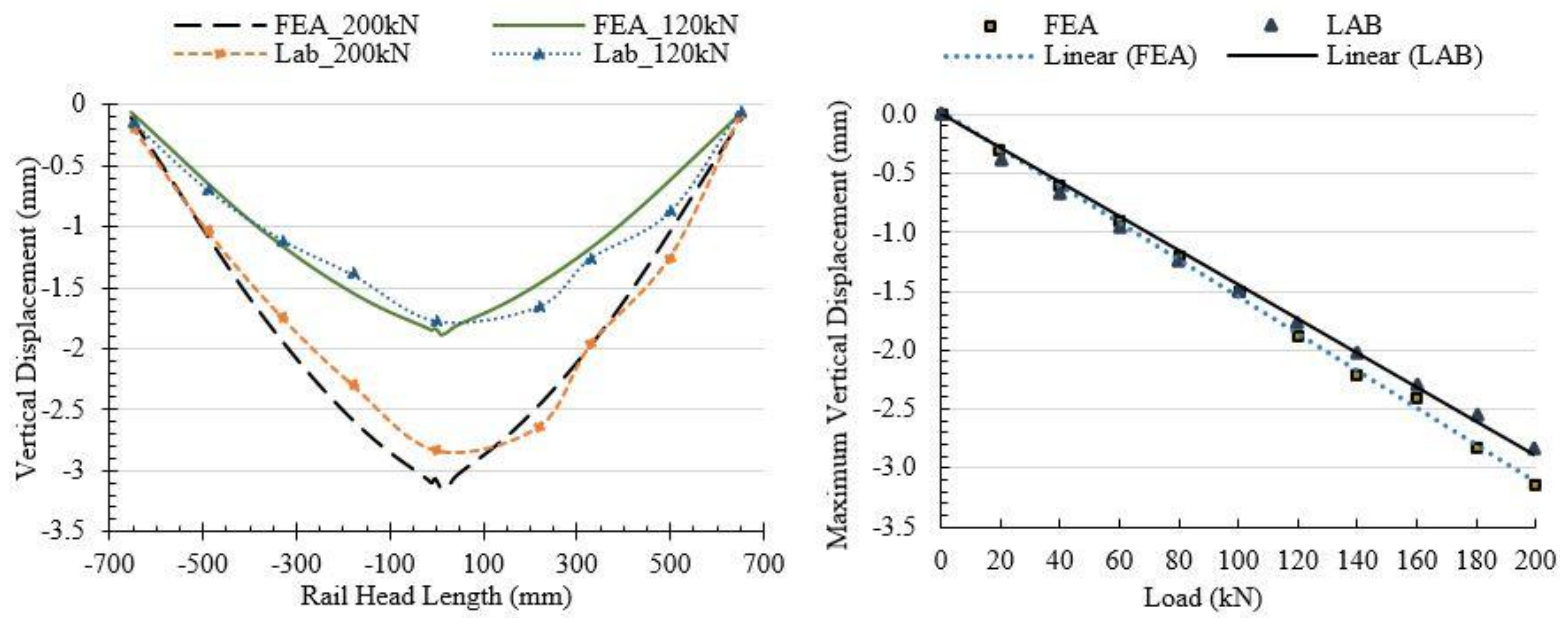

Figure 14 Comparison between Lab and FEA results of the 3-point bend test

\subsection{4-point bend testing}

Laboratory measurements of a 4-bolt glued Class A CEN 60 (1.5 m each rail section) IRJ using high accuracy video technique (Video Gauge) were conducted in a 4-point bend test under cyclic loading (see Figure 15). The geometrical characteristics of the fishplate are presented in

Table 4 . The endpost was of $6 \mathrm{~mm}$ thickness and it was in bonded contact with the rail faces. The two forces were applied at $300 \mathrm{~mm}$ from the gap on the centre of the top of railhead whereas the IRJ was supported at a distance of $800 \mathrm{~mm}$ on each side of the gap. Four load cases were performed from $160 \mathrm{kN}$ to $404 \mathrm{kN}$. It is noted that the extreme load cases selected for this laboratory test were chosen according to the specification [8] to reach mechanical failure of the rail joint, which is out of the scope of this paper. The measured vertical displacement in the centre of the rail joint (rail head edges) was found in a range of $2.29 \mathrm{~mm}$ to $6.11 \mathrm{~mm}$.

Linear static FE modelling to simulate the above 4-point bend test was performed. The model set up (see Figure 16 16) was performed in the same way as described in section 4.1. The maximum deflection in the railhead (same position with the position of Video Gauge measurements) was found $2.58 \mathrm{~mm}$ to $6.23 \mathrm{~mm}$ for the various load cases. A deflection deformation plot is presented in Figure 17Figure 17.

Quite a good correlation was found between the deflections measured by the camera and that found from the FE model. A difference of $2-11 \%$ for the various load cases was found. A comparison between FEA and experimental data is presented in Figure 18.

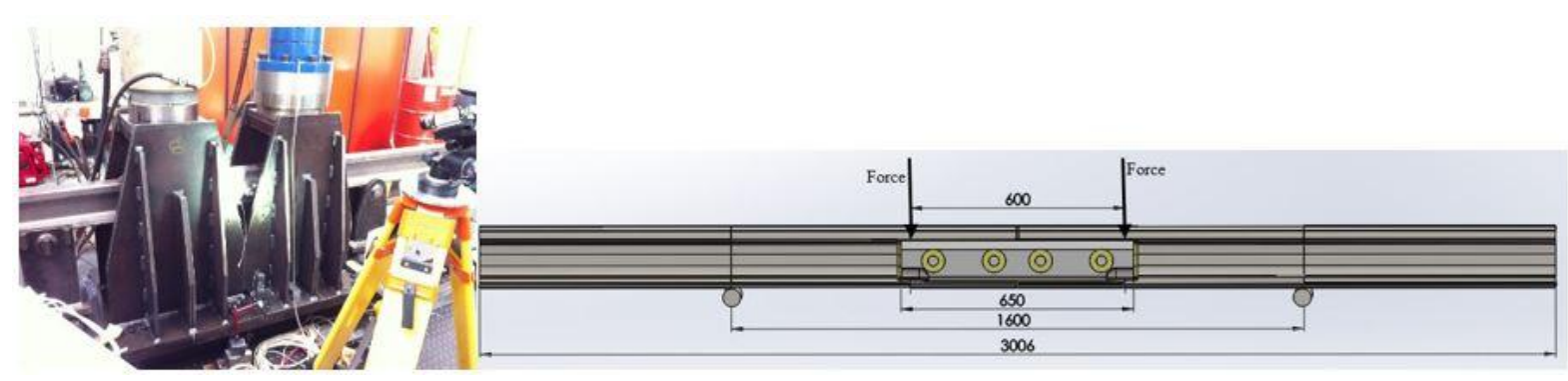

Figure 15 4-point bend configuration 


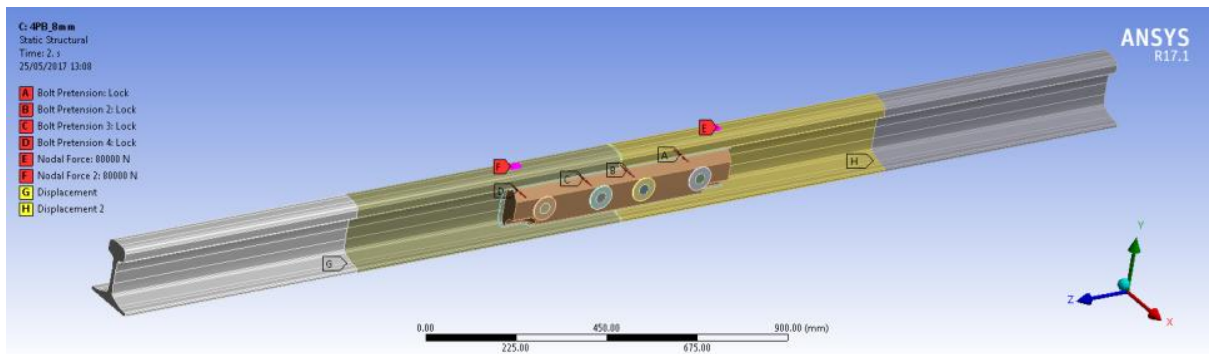

Figure 16 FEA model of 4- point bend configuration

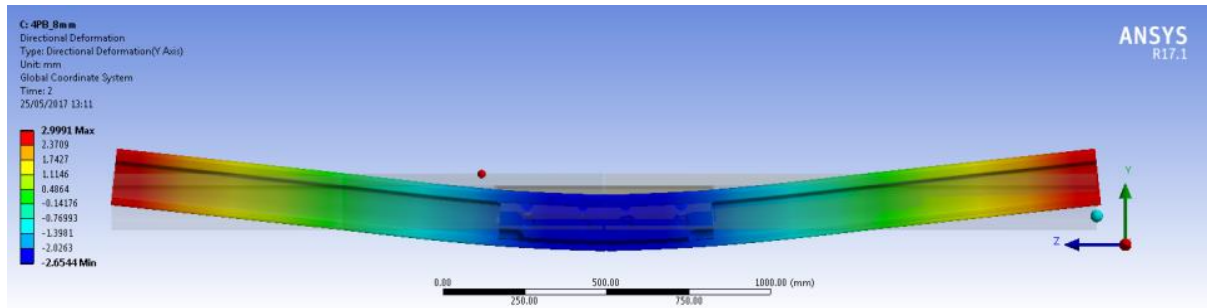

Figure 17 Deformation shape -vertical displacement of 4-point bend-Load case $160 \mathrm{kN}$
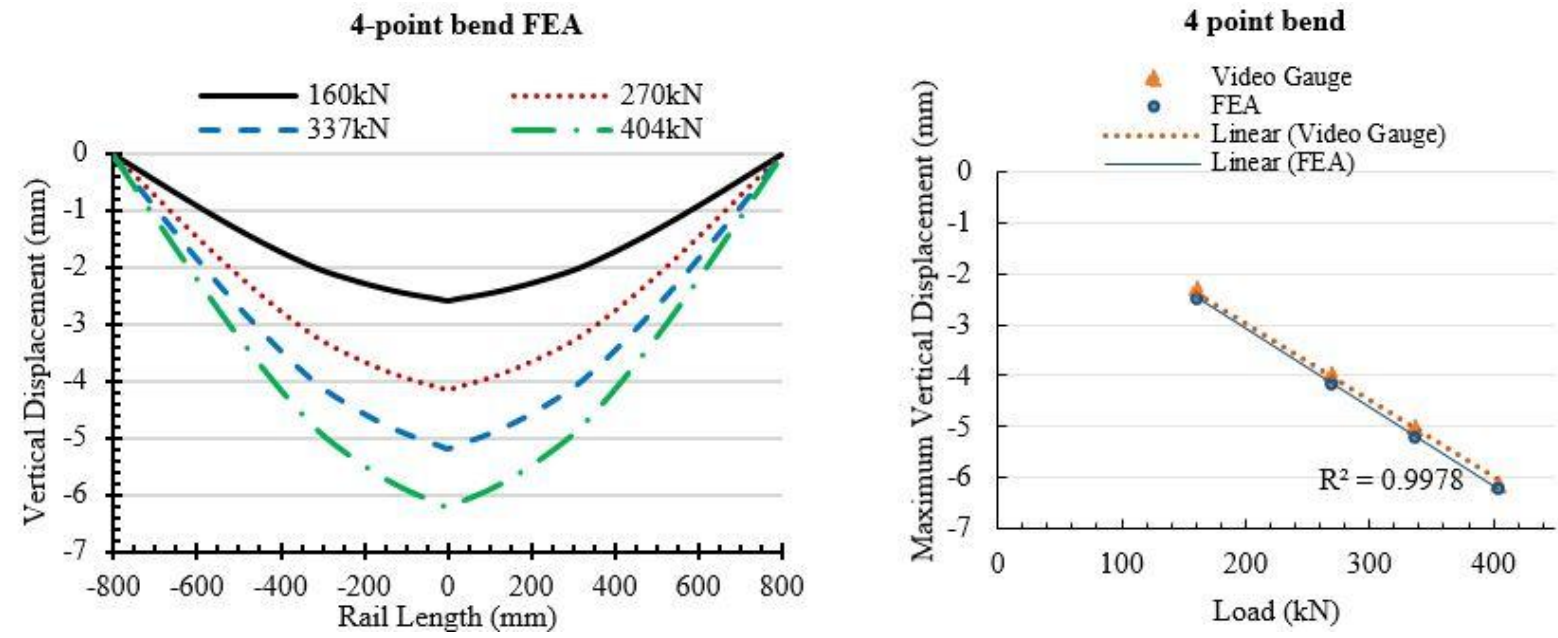

Figure 18 Comparison between FEA data and lab results for the 4-point bend test.

\section{Results from FE analysis}

Results in terms of vertical displacement and equivalent von Mises stresses from the models were displayed for all case studies. Although a strain demonstration at some key points of the model could indicate local weaknesses, this could not be validated against experimental data. In addition, the ultimate scope of this paper's model is to assess IRJs' vertical strength through deflection and to allow through stress-life approach the fatigue life calculation of fishplates and consequently of rail joints due to repeated wheel passage. Equivalent stress allows any arbitrary three dimensional stress rate to be represented as a single positive stress value and is related to the principal stresses by the equation:

$\sigma_{e}=\sqrt{\frac{\left(\sigma_{1}-\sigma_{2}\right)^{2}+\left(\sigma_{2}-\sigma_{3}\right)^{2}+\left(\sigma_{3}-\sigma_{1}\right)^{2}}{2}}$

This stress is part of the maximum equivalent stress failure theory used to predict yielding in a ductile material such as steel. According to this theory, the maximum equivalent stress values are compared to material yield limits (850 MPa) to generate the safety factor

$F_{S}=\frac{S_{y}}{\sigma_{e}}$ 
The maximum vertical displacement found in the centre of rail foot is presented in Figure 19Figure 19.

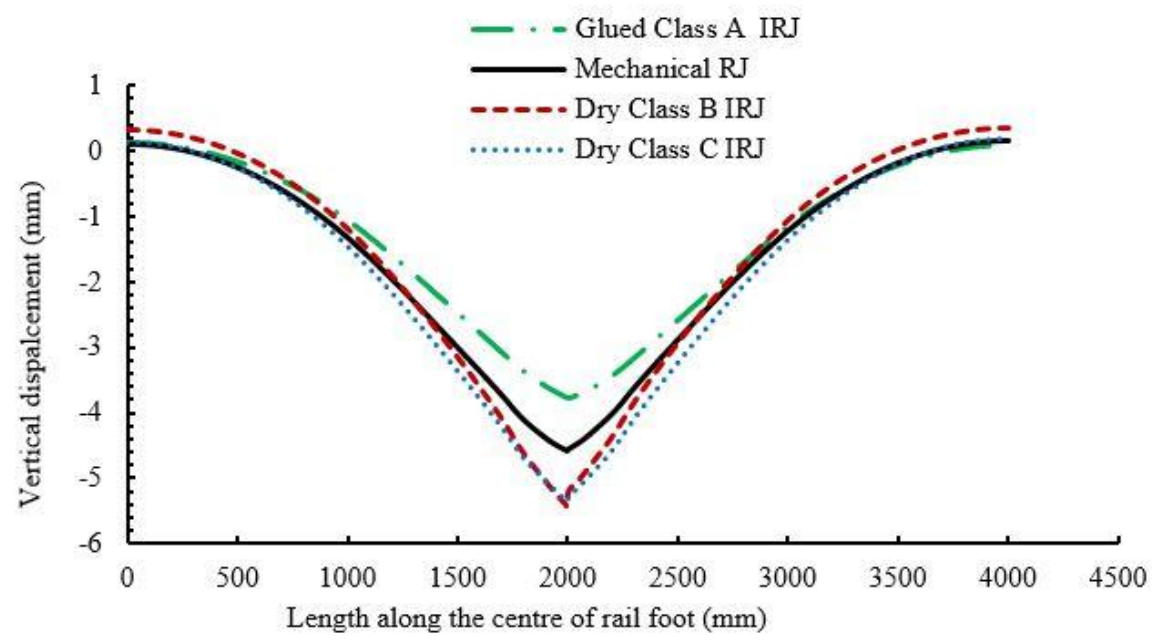

Figure 19 Vertical displacement of the centre of rail foot surface for various rail joint types

Figures 20-23 illustrate the stress distribution of the pair of fishplates for the configurations studied. Figure 24 describes the equivalent stress distribution along the central path at the top and bottom fishing surface of the fishplate for the varying RJ configurations whereas Figure 25 describes the equivalent stress distribution along the central path at the top and bottom fishing surface of the rail.

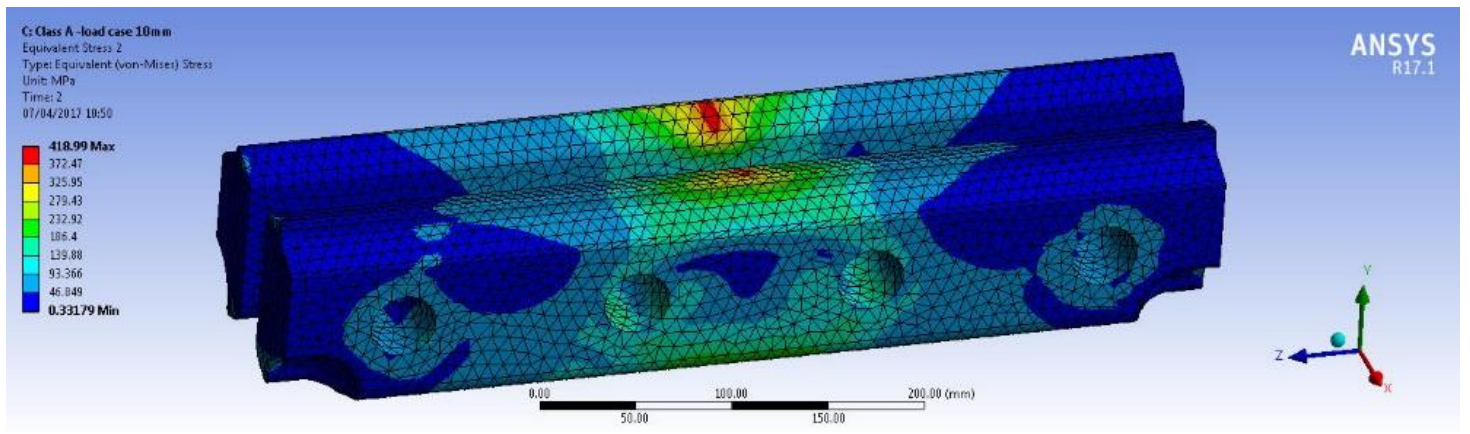

Figure 20 Equivalent (von Mises) stresses - Glued Class A IRJ

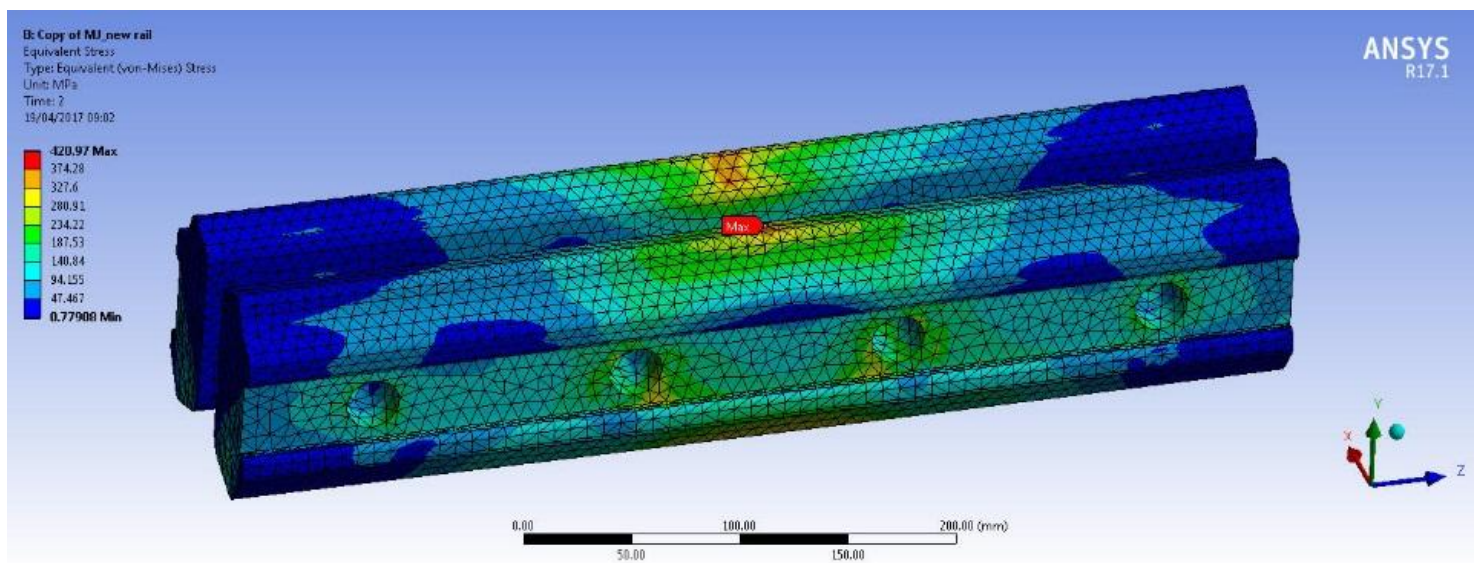

Figure 21 Equivalent (von Mises) stresses - Mechanical RJ 


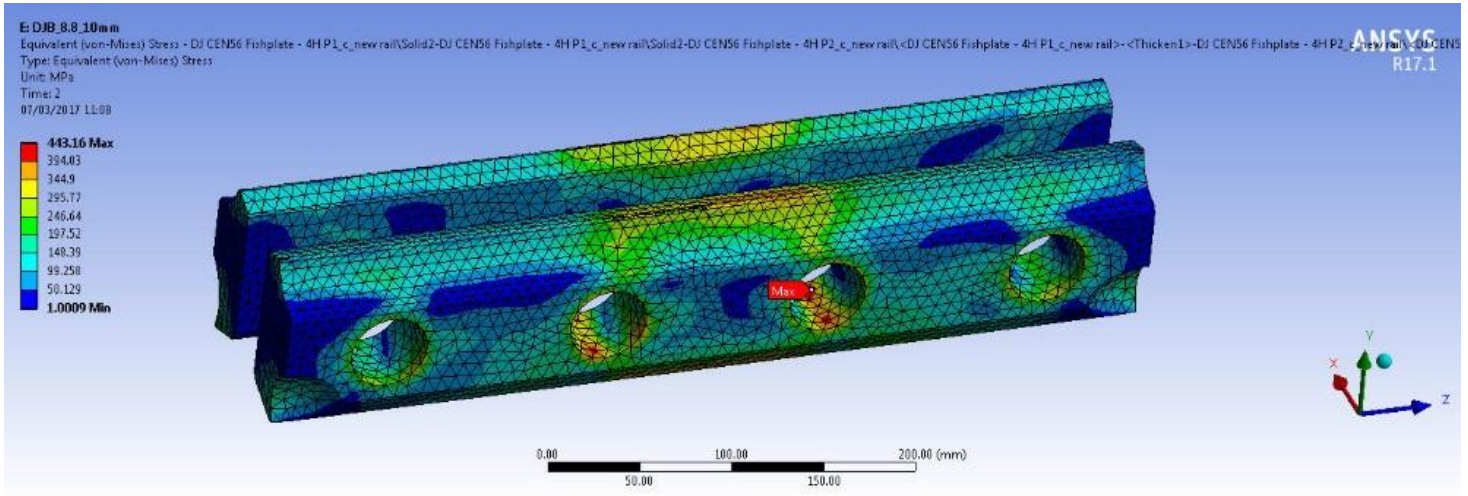

Figure 22 Equivalent (von Mises) stresses - Dry Class B IRJ

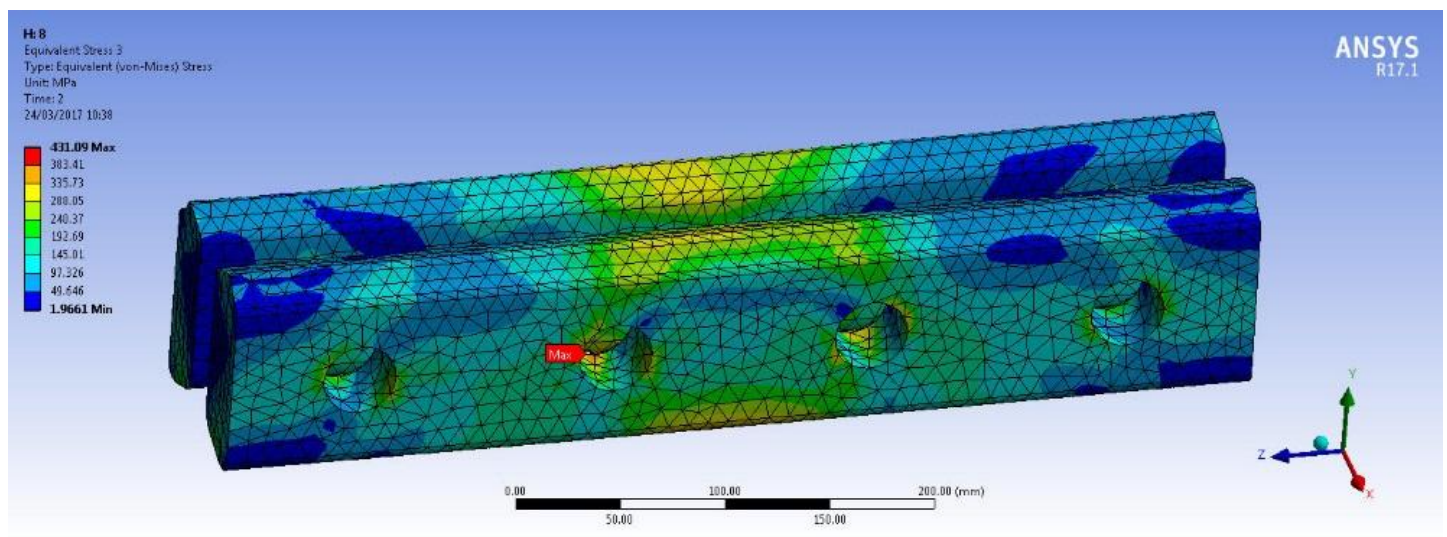

Figure 23 Equivalent (von- Mises) stresses - Dry Class C IRJ
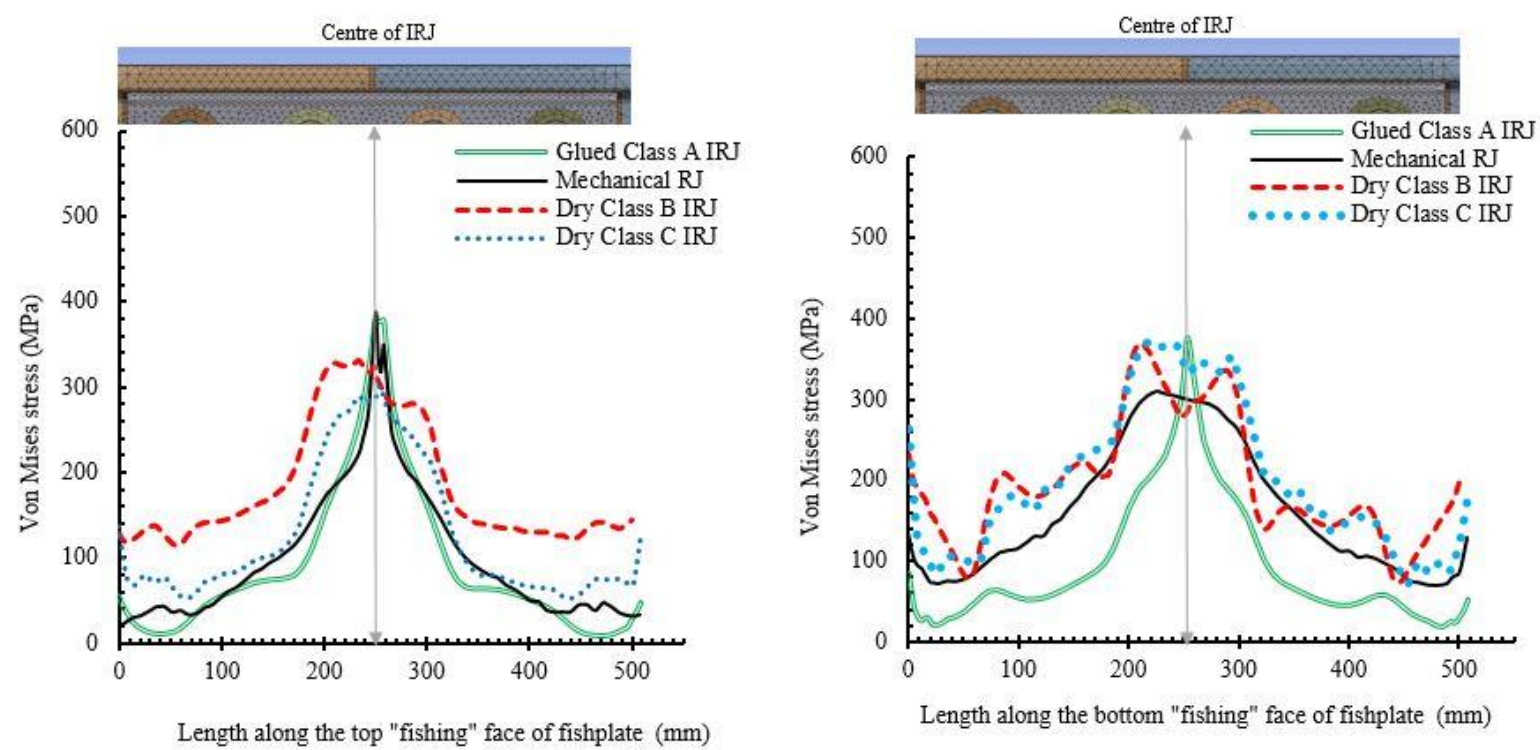

Figure 24 Equivalent (von-Mises) stress plots of the centre of top and bottom fishing surface of the fishplate for various rail joint types 

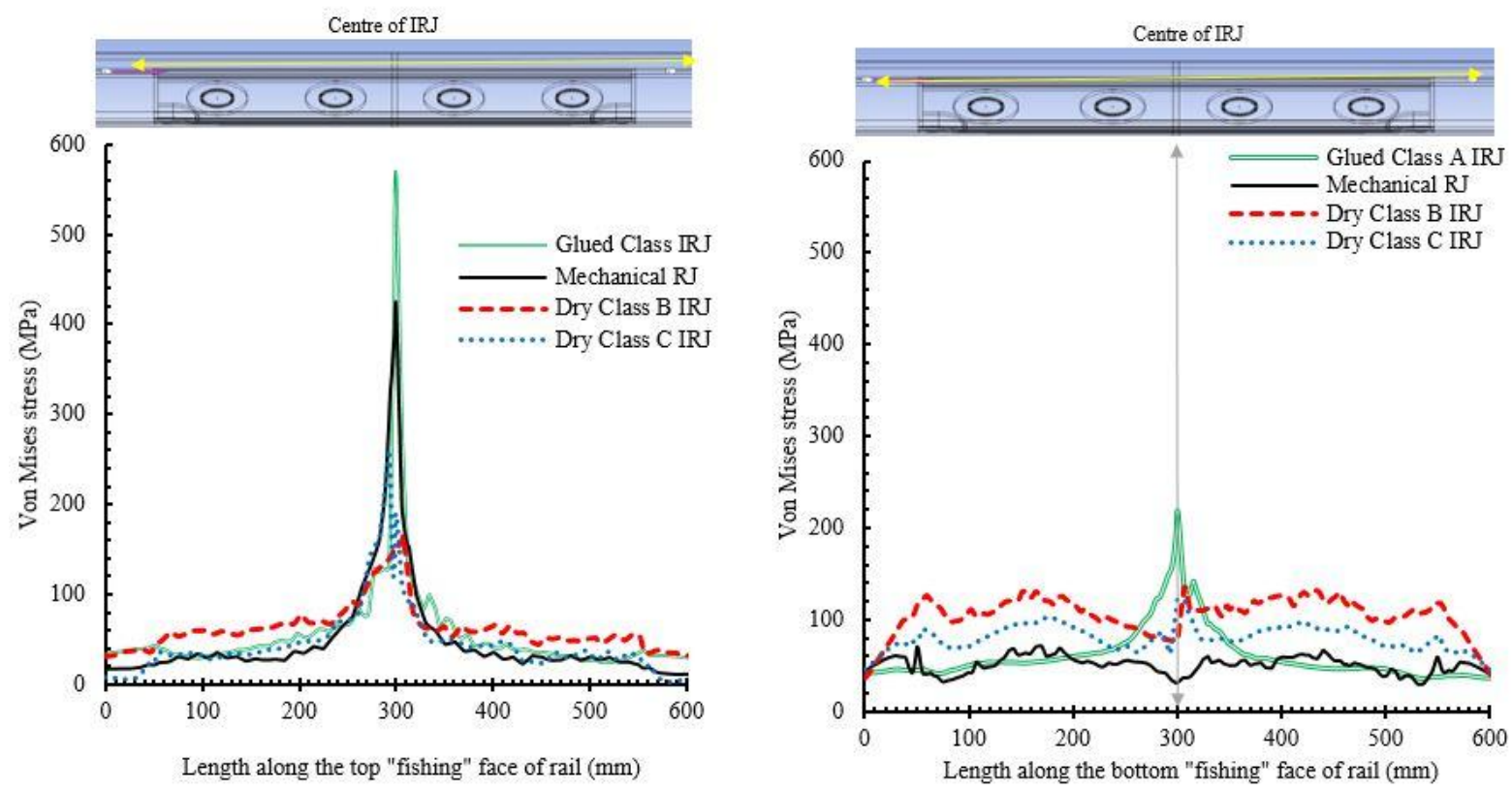

Figure 25 Equivalent (von-Mises) stress plots of the rail head and foot fishing surfaces for various rail joint types

\section{DISCUSSION OF THE RESULTS}

The displacements found here (3.8-5.4mm using a dynamic wheel load of $200 \mathrm{kN}$ and elastic support conditions) accord with real-time dynamic field data measured by the authors (4.2-6.6mm) [22] and are in the same order of magnitude $(2.5-6 \mathrm{~mm})$ with those found in literature $(2.4 \mathrm{~mm}$ for a $150 \mathrm{kN}$ wheel load) [6]. Vertical displacement generally was smaller in the glued IRJ than in the other cases, probably because of the increased contact interfaces. The stresses found in the web face of the fishplates are in agreement with experimental data $[5,7]$. The deflections measured experimentally are within the acceptance criterion of mechanical testing of glued IRJs which is $10 \mathrm{~mm}$ for an applied force of $410 \mathrm{kN}$ [33]. The fishplates, under the input conditions assumed, meet the criteria against yielding for the four cases studied, as the maximum von Mises stresses found in the fishplates are below the yield strength and within the elastic region (absence of plastic deformation). Taken into account the maximum value of the von Mises stresses found in the fishplates, the safety factor was calculated in a range of 1.92-2 >1 for the four cases. Consistent stress plots were observed except peak values of stress that appeared in small areas of the top and bottom fishing surfaces which are due to the location of the wheel directly above the joint leading to high stress concentration in the rail end head -web fillet area and tensile bending stress on the bottom of the fishplate. A stress singularity is noticed in the rail edge in the headweb fillet area in the top fishing surface (this peak is of lower magnitude in the bottom fishing surface) shown in Figure 25. This constitutes a sharp internal corner with a strong change of direction that represent stress concentration with an infinitely small radius. Increasing mesh refinement only serves to increase the stress without limit. Only replacing with a larger fillet would eliminate the singularity. The stress peak is greater in the glued joint because it is a result of the stiffness of the entire model. These results match with recent studies [34] showing that stress in the rail fishing area reaches its maximum when the wheel is above the joint and that even in joints with well adopted easement, high contact pressure is found in the area adjacent to the easement (top and bottom fishing surfaces). It is also considered [34] that the design of the joint (type of rail section, fishplate design) may affect significantly the stress concentration and consequently the fatigue failure initiation on top and bottom fishing surfaces.

Additionally, peak stresses were developed around holes of the fishplates in two of the four cases. These peaks are considered amplified due to localised discontinuities within the model. Peak stresses can occur at local discontinuities (e.g., sharp corners, notches, holes, fillets). Such points are considered as stress singularities [28]. In this study they are attributed to the interaction of the linear beam elements with the fishplate body. The beams were used in place of modelling physical bolts to reduce the model size significantly. Yielding of ductile materials is important when yielding is widespread whereas failure is most often declared when yielding occurs across a complete section. In all instances, no values were recorded in excess of the material yield strength. However, bolt holes can be considered as potential areas of fatigue failure initiation when generated by high positive shear stress concentration around the bolt hole due to the high repeated impact wheel-rail loads and 
deflections [34]. Both bolt hole and top and bottom rail -fishplate interfaces are not detectable with visual inspection in the field.

The highest equivalent stress was found on the dry IRJ Class B (443 MPa). Immediately adjacent to this peak, circa $8 \mathrm{~mm}$ from the hole edge, the equivalent stress values were decreased to $250 \mathrm{MPa}$. Top (circa 332 $\mathrm{MPa}$ ) and bottom (370 MPa) fishing faces of the plate also exhibited increased stress values. This distribution is consistent with the expected "sagging" deformation as a result of the wheel above the joint with compression on the upper and tension in the bottom surface of the fishplate. The corresponding stress values found in the central path of rail fishing surfaces are $166 \mathrm{MPa}$ (top) and $137 \mathrm{MPa}$ (bottom) with higher stress values to appear in the lower curved area of the rail head (240 MPa on top, $300 \mathrm{MPa}$ on bottom). Figure 2121 shows a similar pattern on the mechanical RJ. A peak equivalent stress value of $421 \mathrm{MPa}$ was found on the top fishing surface of the fishplate, however this only occurred around three nodes. Essentially the stresses were found below $250 \mathrm{MPa}$ in the majority of the top fishing area and below $300 \mathrm{MPa}$ in the bottom surface. Peak stresses were also observed in the top fishing surface of the rail.

Parametric analysis of bolt preload for a study when the wheel is not above the joint showed that a $43 \%$ preload decrease, lead to a $37 \%$ decrease of the von Mises stresses developed in the fishplate. However, when the wheel is above the joint, although the effect of bolt preload did exist the effect of vertical load is dominant in the magnitude of von Mises stresses developed.

Class B and class C fishplates developed peak stresses of lower magnitude than that of the mechanical and glued RJs as a result of the encapsulation insulating material and due to the different type of contact that exists in the interface between rail and fishplate. The glued joint developed higher peak stress values due to the increased contact areas among the components of the assembly but experienced less deflection.

The results indicated that the fishplates are experiencing a two-axis bending due to vertical wheel load. The pressure imparted by the underside of the railhead to the fishplate has a vertical and lateral component, due to the curved geometrical area. This fishing curved area induce bending in the fishplates about both its major and minor principal axes. The bolt pretension accounts for a significant percentage of the stresses developed mainly in the fishplate web. The type of FE analysis used here is advantageous over the theoretical approach that cannot take into account the multi-axial stress components.

This paper investigated the deflection and stress distribution around the rail joint area specifically at the railfishplate fishing interfaces, areas that are difficult to be observed in the field for four different types of rail joints commonly used in the UK railway network. This study differentiates from previous studies in terms of the rail joint types studied, the modelling techniques used for each type, the stiffness of the rail joints used (four hole joints that are less stiff than the six hole), the support stiffness of the joints (stiffness per sleeper end) as well as the increased static wheel load $(200 \mathrm{kN}$-arising from an increased static load of $125 \mathrm{kN}$ increased by a dynamic factor of 1.6). The findings of this paper, showing defective areas of stress concentrations in both fishplates and rail fishing areas, can help the track design engineers to improve the efficiency and accuracy of rail joint failure detection and establish new strategies for redesign and maintenance of rail joints. The stress evaluation found by this study is planned to be further used for assessment against fatigue through the endurance limit approach that is mainly used for the analysis of fatigue static tests. This will require stress evaluation of the reverse bending stresses due to hogging deformation of the fishplates, an investigation that is planned to be carried out in the future.

\section{CONCLUSIONS AND RECOMMENDATIONS}

3D finite element analyses were carried out for different rail joint designs to investigate their behaviour under combined biaxial loading in a fatigue static test. Contact non-linearities in the rail joint interfaces and elastic support conditions were taken into account. An increased load case of $200 \mathrm{kN}$, based on real operational data, which has not been covered in past literature was presented. The mechanical response of four rail joint types under vertical load and bolt preload was investigated showing maximum rail joint deflections and areas of stress concentration for both rail and fishplates. The evaluation of stresses for the load case studied here can contribute to the fatigue strength assessment of fishplates as the stress concentrations, the stress multi-axiality and the variable amplitude loading are some of the factors affecting significantly the fatigue integrity of structural components consistent with railway applications. Furthermore, the current research has used FE analysis for proposed RJs that allow designers to use it as a parametric design script template that will enable commercial studies and optimization to improve the life expectancy of IRJs. The model was validated against laboratory testing and correlates well with field measurements.

The results revealed the following conclusions: 
- The top fishing interface between the rail and the fishplate experiences the larger deformation as a result of the wheel load as expected due to the compressive pressure induced.

- The fishplate designs under the increased load case used here developed stresses below the yield limit. The $200 \mathrm{kN}$ wheel load did not cause material plasticity in the rail-fishplate interface.

- The bolt pretension affects significantly the stress level found in fishplate web and dominates for load cases where the wheel is not above the joint. When the wheel is above the joint, the vertical wheel load governs the maximum stress developed.

- The fully glued IRJ type decrease the overall joint displacement by $22 \%$ in comparison with the mechanical RJ and by $42 \%$ in comparison with the dry joints as a result of increased contact in the interfaces of the joint assembly.

- Assessment against fatigue can be performed if reverse bending stresses are calculated for the "hogging" deformation of the fishplates.

\section{Acknowledgements}

The authors wish to thank the Engineering and Physical Sciences Research Council, and Centre for Innovative and Collaborative Construction Engineering at Loughborough University for provision of a grant (number EPG037272) to undertake this research project in collaboration with LB Foster Rail Technologies UK Ltd. The support of Kwan Yiu Derek Lee of Loughborough University in providing the 3-point bend lab test deflection data and of Matthew Holland, Engineering Manager of LB Foster Rail technologies, in providing supportive discussions and advice are gratefully acknowledged.

\section{References}

[1] Beaty P. Experimental testing procedures to investigate and improve insulated rail joint design and life cycle. MSc Thesis, University of Sheffield, UK, 2014.

[2] PWI, Guidance for Heritage Railways on the Inspection and Maintenance of Permanent Way and the Inspection and Assessment of other infrastructure that is necessary for the safety of the line. Document 4Visual inspection. https://www.thepwi.org/technical_hub/guides (2012, accessing 13 June 2017)

[3] Mandal NK, Peach B. An Engineering Analysis of Insulated Rail Joints : A General Perspective. Int J Eng Sci Technol. 2010;2(8):3964-3988.

[4] British Rail Research, Track Unit. Modelling 4-hole fishplated rail joint using the finite element method Report No RR MF 046. Derby, UK, June 1993.

[5] Soylemez E and Ciloglu K. Influence of Track Variables and Product Design on Insulated Rail Joints. Transp Res Rec J Transp Res Board. 2016 Jan;2545:1-10.

[6] Pang T. Studies on Wheel/Rail Contact - Impact Forces at Insulated Rail Joints. MEng Thesis, Central Queensland University, Australia; 2007.

[7] Askarinejad H, Dhanasekar M and Cole C. Assessing the effects of track input on the response of insulated rail joints using field experiments. Proc IMechE, Part F: J Rail Rapid Transit. 2012 Sep 13;227(2):176-187.

[8] NR/SP/TRK/023 Insulated Rail Joints, March 1996

[9] Mandal NK. FEA to assess plastic deformation of railhead material damage of insulated rail joints with fibreglass and nylon endposts. Wear. 2016;366-367:3-12.

[10] Mandal NK and Dhanasekar M. Sub-modelling for the ratchetting failure of insulated rail joints. Int $J$ Mech Sci. 2013;75:110-122.

[11] Himebaugh AK, Plaut RH and Dillard D. Finite element analysis of bonded insulated rail joints. Int $J$ Adhes Adhes. 2008; 28: 142-150.

[12] Grossoni I, Iwnicki S, Bezin Y, et al. Dynamics of a vehicle-track coupling system at a rail joint. Proc IMechE, Part F: J Rail Rapid Transit. 2014; 229:364-374.

[13] Zong N, Wexler D and Dhanasekar M. Structural and material characterisation of insulated rail joints. Electron J Struct Eng. 2013; 13: 75-87.

[14] Patel S, Kumar V and Nareliya R. Fatigue analysis of rail joint by using finite element analysis. Int J Res Eng Technol. 2013; 2: 80-84.

[15] Talamini B, Jeong DY and Gordon J. Estimation of the fatigue life of railroad joint bars. In: ASME/IEEE 2007 Joint Rail Conference and Internal Combustion Engine Division Spring Technical Conference. ASME, 2007, Pueblo, Colorado, USA, 13-16 March 2007. 
[16] Bandula-Heva TM, Dhanasekar M and Boyd P. Experimental Investigation of wheel/rail rolling contact at railhead edge. Exp Mech. 2012; 53: 943-957.

[17] Bandula-Heva T. and Dhanasekar M. Failure of discontinuous railhead edges due to plastic strain accumulation. Eng Fail Anal. 2014; 44:110-124

[18] Sandström J and Ekberg A. Numerical study of the mechanical deterioration of insulated rail joints. Proc IMechE, Part F: J Rail Rapid Transit. 2009; 223: 265-273.

[19] Ding K and Dhanasekar M. Flexural behaviour of bonded-bolted butt joints due to bolt looseness. Adv Eng Softw. 2007; 38: 598-606.

[20] Dhanasekar M and Bayissa W.Performance of square and inclined insulated rail joints based on field strain measurements. Proc IMechE, Part F: J Rail Rapid Transit. 2011. pp1-15

[21] Vossloh Rail Services. Glued Insulated Joint IVB 30. http://www.vossloh-cogiferuk.com/admin/resources/main-content-downloads/vtsivb30.pdf [accessed on 30 June 2017]

[22] Gallou M, Temple B, Hardwick C, Frost M, El-Hamalawi A. Potential for external reinforcement of insulated rail joints. Proc IMechE, Part F: J Rail Rapid Transit. Epub ahead of print 22 Dec 2016.

[23] Van Dyk BJ Van, Dersch MS, Edwards JR, et al. Evaluation of dynamic and impact wheel load factors and their application for design. Transportation Research Board 93rd Annual Meeting. Washington, USA, 12-16 January 2014

[24] British Steel: Steel Grade Composition and Properties, 2017

[25] Cope GH. British railway track: Design, construction and maintenance. 6th ed. Cope GH, England: Permanent Way Institution; 2001.

[26] GC/RT5021:2011. Railway Group Standard. Track System Requirements.

[27] ANSYS Inc. An overview of methods for modelling bolts in ANSYS V15, July 172015.

[28] ANSYS Inc. ANSYS Mechanical User's Guide. Release 17.1, April 2016

[29] prEN 16843:2015 European Standard Railway applications-Infrastructure-mechanical requirements for joints in running rails, March 2015

[30] AREMA- American railway engineering and maintenance of way association, Part 3, Joining of rail. 2007

[31] AS 1085.12-2002 Australian Standard. Reconfirmed 2013 Part 12: Insulated joint assemblies

[32] TB/T 2975-2000 People's Republic of China Standard

[33] NR/SP/TRK/064 Assembly of BR MkIII 4- and 6- hole insulated joints, December 2003

[34] Zhu, K., Y. Qian, J.R. Edwards and B.O. Andrawes. Finite element analysis of rail end bolt-hole and fillet stress on bolted rail joints. Transportation Research Record: Journal of the Transportation Research Board, 2017. 2607: 33-42. 